Made available courtesy of the University of Chicago Press: http://www.press.uchicago.edu/index.html

*** Reprinted with permission. No further reproduction is authorized without written permission from the University of Chicago Press. This version of the document is not the version of record. Figures and/or pictures may be missing from this format of the document.***

\title{
A Structural Model of Child Care and the Labor Supply of Married Women
}

\author{
David C. Ribar, Pennsylvania State University
}

This article empirically examines married women's labor supply and child care expenditures. The article uses winter 1984-85 data from the Survey of Income and Program Participation to estimate a fully structural econometric model of labor supply and paid care utilization. Estimation results indicate that the cost of paid care has small negative effects on labor supply but stronger negative effects on paid care utilization. Consequently, subsidy programs such as the Child and Dependent Care Tax Credit appear to have few effects on married mothers' employment.

\section{Introduction}

Issues related to child care have received extensive public discussion and political debate. Child care has also been the focus of numerous psychological, sociological, and child development investigations. Economists, too, have recently begun to study child care. Clearly, there are many potential areas of inquiry. Several studies have examined the determinants of the family's choice of child care arrangement (Robins and Spiegelman 1978; Leibowitz, Waite, and Witsberger 1988; Lehrer 1989; Hofferth and Wissoker 1992). Economic studies have also examined the relationship between child care and other economic and demographic decisions such

An earlier version of this article was titled "Child Care and the Labor Supply of Married Women: Structural Evidence." I wish to thank Robert Moffitt for useful discussions. I also received helpful comments from Dan Black, Mamoru Ishikawa, Vernon Henderson, Tony Lancaster, Mark Pitt, Mark Roberts, Mark Wilhelm, and workshop participants at numerous agencies and institutions. This research was supported under U.S. Department of Labor grant 99-9-3545-98-078-04.

[Journal of Labor Economics, 1995, vol. 13, no. 3]

(C) 1995 by The University of Chicago. All rights reserved.

0734-306X/95/1303-0001\$01.50 
as mother's employment (Heckman 1974; Blau and Robins 1988; Ribar 1990, 1992; Folk and Beller 1991; Averett, Peters, and Waldman 1992; Berger and Black 1992; Connelly 1992; Leibowitz, Klerman, and Waite 1992; Michalopoulos, Robins, and Garfinkel 1992; Kimmel 1993), fertility (Lehrer and Kawasaki 1985; Blau and Robins 1989), and welfare dependence (Robins 1988a; Connelly 1990). Studies also have examined the broader market for child care services (Ruopp et al. 1979; Blau 1989, 1992; Kisker et al. 1989; Walker 1992).

This study uses winter 1984-85 data from the Survey of Income and Program Participation (SIPP) to examine family demands for paid and unpaid child care services and the effect of these demands on the work effort of married women. In so doing, the analysis explores three distinct questions. First, the study investigates the structure and determinants of child care costs and the extent to which care costs constitute a barrier to employment. Previous analyses have modified standard labor supply models to incorporate alternative descriptions of child care costs. At one level, these analyses are alike in predicting that the need for child care increases the costs of work and decreases the likelihood of labor force participation. Beyond this general result, however, there may be important empirical implications of different assumptions regarding the structure of care costs.

Several studies (e.g., Folk and Beller 1991; Connelly 1992; Michalopoulos et al. 1992) have assumed that conditional on the number of children, the quality of care, and other demographic controls, child care enters the labor supply decision as a flat hourly expense with families paying a fixed amount for each hour the mother works. ${ }^{1}$ Ignoring taxes and subsidies, such costs simply lower the mother's net hourly wage and are predicted to have negative effects on her labor force participation and ambiguous effects on overall hours of work. Another set of studies (Cogan 1980; Blau and Robins 1988; Robins 1988a) have examined child care as a fixed cost of workthat is, as a lump sum expense which is imposed as a condition of employment but does not vary thereafter with the level of employment. Fixed costs effectively reduce employed mothers' unearned incomes while leaving nonemployed mothers' incomes unchanged. The resulting notch in the budget constraint leads to a discontinuous labor supply function and different effects for alternative groups of women. Specifically, fixed care costs are expected to reduce employment among mothers with relatively weak labor force attachments but increase labor supply among those with strong attachments. Finally, consider a description of costs that lies between these two extremes, where child care expenditures increase with hours of work but do so at a decreasing rate. As with fixed care costs, the presence of

${ }^{1}$ In the case of Folk and Beller (1991), families pay a fixed amount for each hour that the parents' work schedules overlap. 
decreasing marginal costs leads to a nonconvex budget set and, possibly, a discontinuous labor supply function.

Given that each of the preceding specifications represents a theoretically plausible description of care expenditures, selecting the appropriate specification becomes an empirical issue. Descriptive data from the U.S. Bureau of the Census (1992) suggest that child care expenditures may not vary linearly with labor supply. In particular, the Census Bureau reports that in 1988 women who worked fewer than 10 hours per week paid an average of $\$ 6.06$ per hour for care, while women who worked 10 or more hours paid an average of $\$ 1.78$ per hour. Unfortunately, other than the Census Bureau study, there is little hard evidence regarding the structure of care costs. ${ }^{2}$ A key task for the present study will be to examine the empirical relationship between child care expenditures and labor supply.

A second important research issue is to recognize that not all working mothers need or use paid child care. Indeed, data from the U.S. Bureau of the Census (1992) indicate that in 1988, 60\% of employed mothers with at least one child under the age of 15 and $32 \%$ of working mothers with a child under the age of 5 used unpaid care exclusively. Similar to most of the existing research on child care and women's employment, this study treats paid care utilization as an endogenous decision which is made simultaneously with the woman's work decision. The article develops a model that describes the benefits, direct costs, and opportunity costs of paid care utilization. In the model, the principal benefit of paid care is its contribution to overall child quality. The monetary expense of paid services represents the direct cost, and the relative quality of available unpaid arrangements represents the opportunity cost of paid care.

The model also recognizes that the relative attractiveness of paid care utilization may vary with hours worked (e.g., the marginal cost of paid care and the availability of unpaid care may both decrease with hours). This supposition is supported by the U.S. Bureau of the Census (1992) data which suggest that in 1988 women who were employed full-time were $50 \%$ more likely than women who worked part-time to use paid care. With the exception of Folk and Beller (1991) and Michalopoulos et al. (1992), previous studies of child care and work effort have not examined the effect of work hours on paid care utilization.

A third goal of this article is to examine how taxes and tax subsidies affect married women's care utilization and labor supply decisions. The effect of the U.S. tax system on labor supply has been extensively researched

${ }^{2}$ Kimmel (1993) examined three different marginal cost specifications-average cost of care per hour worked, average cost per hour worked per child in paid care, and average cost per hour of paid care used per child. Hotz and Kilburn (1991) presented descriptive evidence of the determinants of total costs and average hourly costs per child for working and nonworking women. 
(see, e.g., Hausman 1981). There have also been attempts to investigate the labor supply effects of free center-based care (Robins 1988a), subsidies to low-income single parents (Berger and Black 1992), child care tax subsidies (Ribar 1990, 1992; Averett et al. 1992; Michalopoulos et al. 1992), and child care subsidies generally (Blau 1989).

Taxes and subsidies introduce nonlinearities into the household budget constraint. As an illustration, consider the case of a married couple with one child in 1985 in which the couple had no unearned income, the husband had an annual earned income of $\$ 5,000$, and the wife had an available wage rate of $\$ 3.50 .^{3}$ Assuming that the couple paid social security taxes, took the standard deductions, exemptions, and available credits, and did not pay for child care, the wife's effective budget constraint is described by figure $1 a$. Examining figure $1 a$, there is a convex kink at hours point $A$ (the maximum hours at which the family could claim the full value of the Earned Income Tax Credit [EITC]), a convex kink at $B$ (the point at which the family had positive taxable income), and a nonconvex kink at $C$ (the point at which the EITC would be exhausted).

Figure $1 b$ depicts the same family's budget constraint but assumes that they paid child care costs of 75 cents for each hour the mother worked. In the absence of subsidies, the budget constraint has a flatter slope but essentially the same shape as before. However, the family could have reduced its tax liability by the amount of the nonrefundable Child and Dependent Care Tax Credit (CDCTC). ${ }^{4}$ In this case, the CDCTC would exceed the family's tax liability at every point along the budget constraint. Thus, once the EITC was exhausted, the family would pay only the social security tax, resulting again in a nonconvex kink at $C$.

Estimation of care utilization and labor supply functions becomes substantially more complicated in the presence of nonlinear budget constraints like those described earlier and those depicted in figures $1 a$ and $1 b$. One obvious complication involves the computation of effective wage rates,

\footnotetext{
${ }^{3}$ These figures are obviously not representative of all families. The figures were selected to demonstrate the interaction of tax and subsidy programs for low-income families. There are other kinks and notches in the budget constraints for middleand upper-income families.

${ }^{4}$ The CDCTC ranges from $30 \%$ of eligible child care expenditures for families that earn less than $\$ 10,000$ per year to $20 \%$ of care expenditures for families that earn more than $\$ 28,000$. Eligible expenditures are $\$ 2,400$ per year for one child and $\$ 4,800$ for two or more children. Thus, the maximum credit is $\$ 720$ for one child or $\$ 1,440$ for two or more children. However, due to its nonrefundability, few families receive these maximum amounts. In 1985 the CDCTC cost the federal government $\$ 3.128$ million (U.S. Department of the Treasury 1988). This represents roughly $60 \%$ of all federal child care expenditures for 1985 .
} 


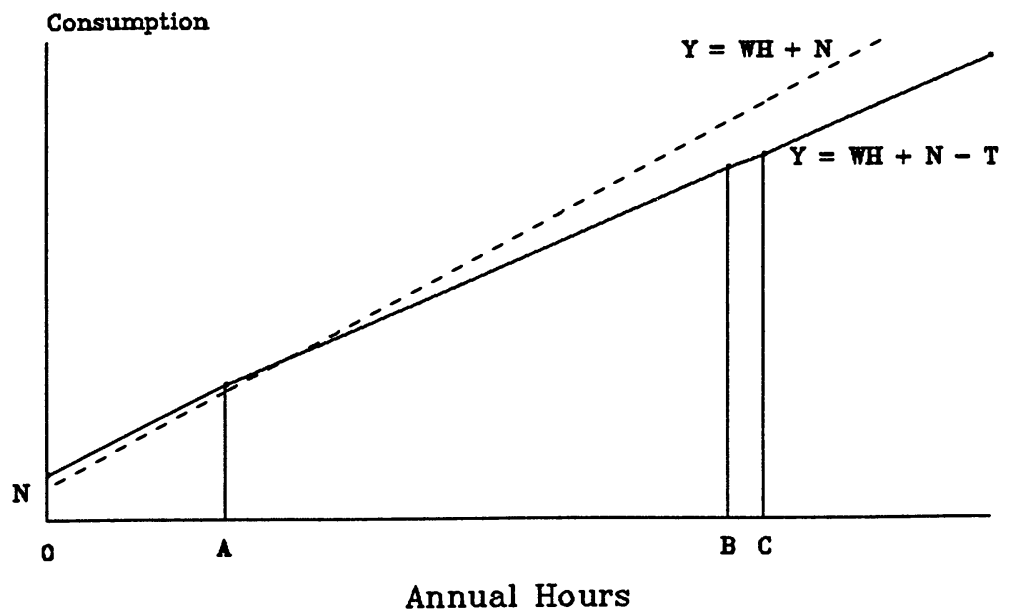

-- Pre-Tax Income After-Tax Income

$a$

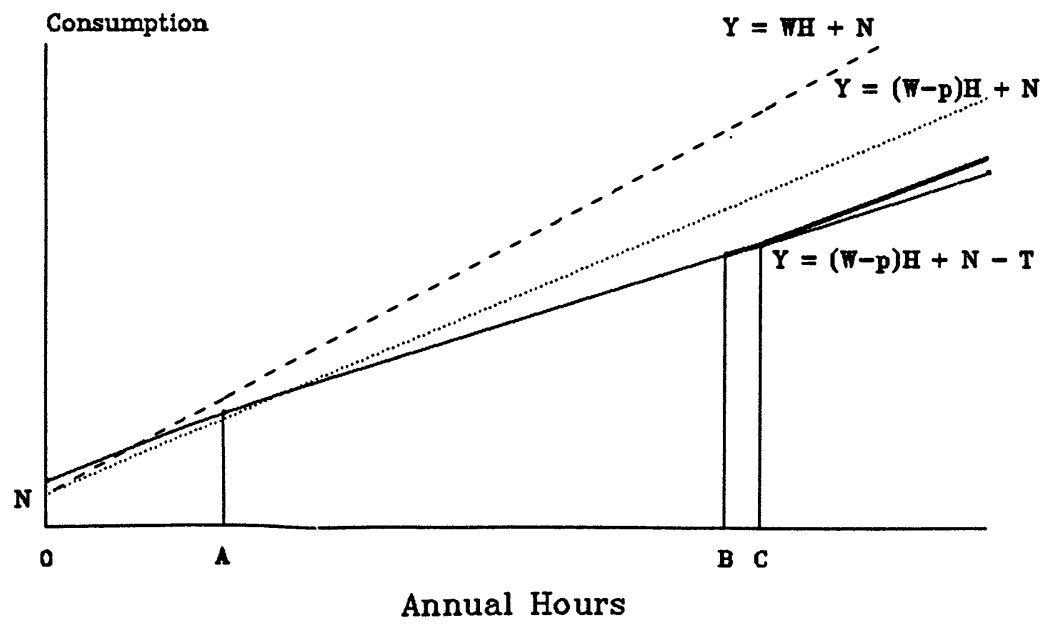
- Net Income, No CDCTC

FIG. 1.-Income net of taxes: $a$, without care costs; $b$, with care costs

marginal costs, and incomes. Another problem is that families' observed locations along the budget set depend on their preferences and are not generated entirely at random. Thus, the estimation procedure must account 
for the possibility of self-selection in the effective wages and marginal costs. ${ }^{5}$

Previous child care studies have adopted different strategies in trying to correct for this type of selectivity. Ribar (1990) and Michalopoulos et al. (1992) estimated partially structural models and used instruments for aftertax wages and care costs. In principle, structural estimators derived directly from the family's preference function facilitate nonlinear budget constraint estimation by providing an explicit representation of the source of selectivity. Structural methods also yield estimates of preference parameters which are independent of the budget constraint, thereby facilitating detailed policy simulation. Unfortunately, neither Michalopoulos et al. nor Ribar implemented the full set of restrictions implied by their respective structural models; moreover, neither study estimated all of the preference parameters necessary for simulation exercises. ${ }^{6}$ Using an alternative econometric approach, Averett et al. (1992) examined the labor supply effects of care costs and the CDCTC. Their model incorporated all of the selectivity restrictions implied by nonlinearities in the convex portion of the CDCTC. However, the model did not consider any other features of the tax system and did not address the endogeneity of paid care utilization.

This article estimates a fully structural, discrete-choice model of married mothers' care arrangements and labor supply. In particular, the article develops a full-information maximum likelihood specification which relies on direct utility comparisons over women's decisions to work zero, parttime, or full-time hours and utilize paid or unpaid care. This approach extends the previous work of Michalopoulos et al. and Ribar by providing estimates of all of the relevant utility parameters and by allowing effective wages and care costs to vary across alternative work and care utilization states. Unlike Averett et al., the article's empirical specification incorporates general features of the tax system including nonconvex regions of the CDCTC.

Estimation reveals that married women's labor supply is relatively sensitive to changes in hourly wages but insensitive to changes in care costs. Among employed women who pay for care, an increase in care costs ap-

${ }^{5}$ Appropriate estimation methods are reviewed by Hausman (1985) and Moffitt (1990).

${ }^{6}$ Michalopoulos et al. (1992) estimated structural care expenditure and labor supply functions conditional on reduced-form labor force participation and paid care utilization equations. Their procedure did not explicitly examine the determinants of unpaid arrangements. Ribar (1990) estimated structural paid and unpaid care utilization equations conditional on a reduced-form specification for labor supply; his study did not examine the structural determinants of work decisions. Both studies used an instrumental variables approach which eliminated the endogeneity of wages and prices but did not incorporate budget-induced selectivity restrictions. 
pears to increase the attractiveness of unpaid nonmaternal arrangements rather than maternal care. Overall, mothers with preschool-age children are found to be less sensitive to wage and care cost changes than other mothers. Simulations based on the article's structural estimates are conducted to examine the behavioral implications of alternative tax and subsidy policies. The simulations indicate that the existing CDCTC has a modest positive effect on labor supply and a stronger positive effect on paid care utilization.

The remainder of this article is organized as follows. Section II develops a conceptual model of child care and hours of work. An empirical representation of that model is derived in Section III. Section IV describes the data sources and the analysis extract. Estimation results and policy simulations appear in Section V. The paper concludes in Section VI.

\section{Conceptual Model}

Consider a 1-period model in which a family has preferences over market goods, $C$, the quality of care extended to its children, $Q$, and the mother's hours devoted to nonmarket activities, $L .^{7}$ Let those preferences be represented by a direct utility function, $U=U(C, Q, L)$ where utility is increasing in $C, Q$, and $L$. The labor force participation of the father is assumed to be predetermined and, hence, exogenous. The static framework also implicitly treats the parents' prior family formation, fertility, education, and savings behavior as exogenous variables.

Denote the mother's hours spent working in the market by $H$. The mother's total available time, $K$, can be divided between market and nonmarket activities such that

$$
K=H+L \text {. }
$$

Nonmarket hours, $L$, are defined to include maternal child care, other household production activities, and leisure.

Besides the care they receive from their mother, children can receive care from paid and unpaid sources. ${ }^{8}$ Let $F$ be a dichotomous variable which

${ }^{7}$ Because the model effectively examines only one decision maker, it can easily be extended to single-parent families. The article's focus is limited to married mothers for reasons of sample homogeneity and tractability. Married and single mothers face very different opportunity sets. Married mothers have the potential time and income resources of their husbands. Married mothers' budget constraints are also less likely to be complicated by transfer kinks.

${ }^{8}$ Limiting the family's choice set to paid and unpaid arrangements represents a strong, restrictive assumption. The reduced choice set may group together very different types of care. The caution applies more to paid than unpaid care. Kisker et al. (1989) found that unpaid arrangements generally represented unregulated care by relatives and neighbors. In contrast, paid care contains three qualitatively distinct arrangements-licensed (regulated) care, other nonrelative care, and relative care. The restriction to paid and unpaid care is imposed in this article for comparability with existing research and for tractability of the econometric model. 
equals one if the family utilizes any paid care and which equals zero if the family utilizes maternal or unpaid nonmaternal care exclusively. Total care quality for the family's children depends on inputs of maternal care, paid and unpaid nonmaternal care, and other goods. Specifically, let

$$
Q=Q\left(L, F, C ; \boldsymbol{\alpha}_{\mathrm{Q}}\right),
$$

where $\alpha_{Q}$ represents a set of conditioning factors (e.g., number and age distribution of children, parents' education, safety of the children's neighborhood) which affect the production of care quality. Care quality is assumed to increase with inputs of maternal care and market goods. The contribution of $F$ to overall quality is ambiguous and depends on the quality of paid care relative to maternal and unpaid nonmaternal care. For simplicity, the relative quality of paid care conditional on $\alpha_{Q}, L$, and $C$ is assumed be exogenously determined. ${ }^{\text {? }}$

Paid child care is priced in terms of consumption goods, $C$. Let the cost of paid care services be given by $P_{F}=P_{F}\left(H ; \alpha_{P}\right)$, where costs depend on the mother's hours of work and a set of conditioning factors, $\alpha_{P}$. Families are assumed to take the cost schedule as given. Letting $W$ represent the mother's available hourly wage rate, the budget set can be expressed as

$$
C=W H+N-P_{F}\left(H ; \alpha_{P}\right) F=Y(H, F),
$$

where $N$ denotes nonlabor income and $Y$ denotes total income. The earnings of others in the household aside from the mother are included in $N$ and taken to be exogenous.

Notice that paid care utilization enters the model in two ways. Market care services may enter beneficially as an input to the production of child care quality. Market services also appear in the budget constraint and are assigned an explicit cost $P_{F}$. In contrast, unpaid services enter the model only as an input to the production of quality. Thus, the decision to utilize paid or unpaid care depends only on the absolute cost and relative quality of paid care. The availability and possible nonpecuniary cost (e.g., room and board, reciprocating time transfers) of unpaid care are not explicitly considered.

To remedy this omission, this article assumes that nonmarket care is available to all families at some indirect cost and respecifies the model to include such costs. ${ }^{10}$ In particular, let the indirect cost of unpaid care be

${ }^{9}$ Thus, other than conditioning on $\alpha_{\mathrm{Q}}, L$, and $C$, this approach makes no distinction between high- and low-quality paid care. A further limitation is that the approach does not consider alternative dimensions of "quality" such as convenience and dependability.

${ }^{10}$ Descriptions and evaluations of alternative restrictions appear in Ribar (1990). 
the value of the care provider's time in alternative activities. This description provides a suitable measure of the availability of unpaid care. If nonmarket care is provided for some nonpecuniary consideration, the indirect cost could capture the value of this transaction as well.

Indirect costs might be incorporated into the model in one of two ways. First, indirect costs could enter as a shadow expense into the family's level of consumption. This explicit representation of indirect costs has the advantage of providing a symmetric treatment of paid and unpaid care. Unfortunately, the approach requires that the budget constraint be modified to include a "full income" measure for the caregiver's other potential contributions to the household. An alternative approach which is adopted by this article is to incorporate indirect costs directly into the utility function. Specifically, the article reexpresses the preference function as $U=U(C$, $Q, L, F)$, where utility increases in consumption goods, care quality, leisure, and paid care utilization (i.e., decreases in unpaid care utilization). The (dis)utility term acts as a flexible and tractable proxy for the indirect costs of unpaid care. Indeed, the term nests the properties of the shadow cost approach. The chief disadvantage of the utility approach is that it is theoretically clumsy. While the modified utility function captures the effects of indirect costs, there is no reason to suppose that families actually have direct negative preferences regarding unpaid care.

With this modification, the family's decision can now be modeled as a standard maximization problem. Let the choice variables be $H$ and $F$. Substituting equations (1), (2), and (3) into the utility specification, the family's problem becomes

$$
\max _{H, F} U=U\left\{Y(H, F), Q\left[K-H, F, Y(H, F) ; \alpha_{Q}\right], K-H, F\right\},
$$

subject to nonnegativity constraints for the two choice variables.

Assuming that the budget constraint is convex and that (4) is differentiable, the first-order condition for (4) with respect to $H$ can be manipulated to produce an expression for the mother's reservation wage. Substituting $H=0$ into the first-order condition and expressing the condition as an equality yields

$$
W_{R}=\left.\frac{\partial P_{F}}{\partial H}\right|_{H=0}+\left.\frac{U_{Q} Q_{L}+U_{L}}{U_{Q} Q_{C}+U_{C}}\right|_{H=0},
$$

where $U_{C}, U_{\mathrm{Q}}, U_{L}, Q_{C}$, and $Q_{L}$ represent the partial derivatives of the utility and quality production functions with respect to the subscripted arguments. Several conditional comparative static results can be derived for the reservation wage. Holding nonmaternal child care utilization con- 
stant, equations (4) and (5) imply that the reservation wage decreases with the marginal utility of consumption and the marginal contribution of consumption goods to care quality. The reservation wage increases with the marginal cost of paid care, the marginal utility of nonmarket time, and the marginal contribution of nonmarket time to care quality. These conditional results are similar to the predictions generated by Blau and Robins (1988).

An expression for the reservation expenditure on paid care can also be derived. Define $P_{F}^{*}$ to be the level of paid care expenditures that leave families indifferent between utilizing paid and unpaid care. Writing $P_{F}^{*}$ as an implicit function, $P_{F}^{*}$ satisfies

$$
\begin{gathered}
U\left\{W H+N-P_{F}^{*}, Q\left[K-H, 1, W H+N-P_{F}^{*} ; \alpha_{\mathrm{Q}}\right], K-H, 1\right\} \\
=U\left\{W H+N, Q\left[K-H, 0, W H+N ; \alpha_{\mathrm{Q}}\right], K-H, 0\right\} .
\end{gathered}
$$

The likelihood of paid care utilization increases with the marginal utility of paid care and the marginal contribution of paid care to overall child quality. Families are less likely to use paid care if their preferences for consumption are strong or the marginal contribution of market goods to child quality is high.

\section{Econometric Specification}

The article derives a structural econometric model which is based on direct utility comparisons over different care utilization and labor supply alternatives. To obtain its econometric specification, the article imposes several restrictions on the theoretical model. First, the article adopts a parametric specification for the family's preference function. Note that the objective function in (4) can be written as a function of income, labor supply, and paid care utilization. The article expresses the objective function as a generalized quadratic in these three arguments such that

$$
\begin{aligned}
\max _{H, F} U= & \tilde{U}(Y(H, F), H, F) \\
= & Y(H, F)-\theta_{C} Y(H, F)^{2}+\beta_{b} H-\theta_{b} H^{2} \\
& +\beta_{f} F+\gamma_{c h} Y(H, F) H \\
& +\gamma_{c f} Y(H, F) F+\gamma_{b f} H F
\end{aligned}
$$


Specification (7) can be interpreted as a flexible approximation to (4) in which the coefficients represent combinations of utility and care quality production parameters. ${ }^{11}$

Second, the article restricts the family's choice set by limiting the mother's possible labor supply outcomes to zero, part-time, or full-time hours and by assuming that families with nonworking mothers utilize no paid care. ${ }^{12}$ These restrictions imply that each family chooses from among five options: (1) mother does not work, (2) mother works part-time and uses unpaid care exclusively, (3) mother works full-time and uses unpaid care exclusively, (4) mother works part-time and uses paid care, and (5) mother works full-time and uses paid care.

As written, specification (7) implies that differences in mothers' care utilization and labor supply decisions are generated entirely by differences in their effective wages, care costs, and unearned incomes. The article introduces additional heterogeneity into (7) by respecifying the marginal parameters on hours of work and the interaction of hours of work and paid care to be functions of observed and unobserved components. That is, let

$$
\beta_{b}=\delta^{\prime} Z+\eta, \quad \text { and } \quad \gamma_{h f}=\psi^{\prime} X+\varepsilon,
$$

where $Z$ and $X$ are vectors of observed determinants and $\eta$ and $\varepsilon$ are error terms. The error terms are assumed to follow a bivariate normal distribution such that

$$
\left[\begin{array}{l}
\eta \\
\varepsilon
\end{array}\right] \sim N\left(\left[\begin{array}{l}
0 \\
0
\end{array}\right],\left[\begin{array}{cc}
\sigma_{\eta}^{2} & \rho_{\eta \varepsilon} \sigma_{\eta} \sigma_{\varepsilon} \\
\rho_{\eta \varepsilon} \sigma_{\eta} \sigma_{\varepsilon} & \sigma_{\varepsilon}^{2}
\end{array}\right]\right) .
$$

With these assumptions, derivation of a maximum likelihood estimation method is straightforward. Specifically, data on families' care and maternal employment decisions provide information on their relative valuations of the five options. The choice of a particular option implies that the utility associated with that option is at least as great as the utility associated with each of the other options. Pairwise comparisons of the utility functions

"Though flexible, the generalized quadratic specification has some disadvantages. The function is not globally concave and not guaranteed to be increasing in income across its entire range. Ribar (1990) discusses alternative utility specifications.

${ }^{12}$ The first restriction is imposed for tractability. The second reflects a data constraint-care utilization is unobserved for nonworking mothers in the SIPP-and may not be entirely reasonable. Using data from the National Longitudinal Study of the High School Class of 1972, Hotz and Kilburn (1991) found that nearly a quarter of nonworking married mothers with preschool-age children used some form of nonparental care. 
lead to a set of truncation restrictions on the error terms $\eta$ and $\varepsilon$. These restrictions combined with the distributional assumptions (9) in turn yield parametric descriptions of the probabilities associated with each choice. Let $d_{i j}$ be a binary variable which equals one if family $i$ selects choice $j$ and zero otherwise. For a sample of $N$ families, the likelihood function is given by

$$
L F=\prod_{i=1}^{N}\left[\sum_{j=1}^{5} d_{i j} \operatorname{prob}\left(d_{i j}=1\right)\right] .
$$

Precise descriptions of the choice probabilities in (10) are provided in appendix A.

The likelihood function is maximized using the algorithm developed by Berndt et al. (1974). Some complications arise, however, in applying this procedure. In particular, the utility comparisons yield truncation conditions which are piecewise linear functions in the error terms. Thus, the choice probabilities in (10) must be evaluated using numerical methods. ${ }^{13}$ Moreover, the presence of kinks in the truncation conditions implies there are points in the parameter space where the likelihood function is not differentiable. Such nondifferentiability can lead to convergence and inference problems in the Berndt et al. procedure. ${ }^{14}$

Similar models based on direct utility comparisons have been used in other studies (e.g., Fraker and Moffitt 1988; Keane and Moffitt 1991; Moffitt and Wolfe 1992). Like those models, the present specification is essentially a nonlinear multinomial choice model. The specification is fully structural in the sense that estimates of all of the relevant objective function parameters from (7), (8), and (9)-namely, $\beta_{f}, \theta_{c}, \theta_{b}, \gamma_{c b}, \gamma_{c f}, \delta, \psi, \sigma_{\eta}, \sigma_{\varepsilon}$, and $\rho_{\eta \varepsilon}$-are identified. Identification is secured through functional and distributional assumptions which lead to nonlinearities in (10). In addition, the article employs exclusion restrictions on the vectors $Z$ and $X$. Along with providing estimates of the preference parameters, the structural procedure allows effective wages and care costs to vary across alternatives. The procedure can also be applied to nonconvex budget sets. The chief disadvantage of the specification is the restricted choice set. Unfortunately, expanding the number of care and work alternatives results in more complicated error truncation conditions.

There are two remaining data issues. First, available wages are unobserved for mothers who are not employed. The analysis imputes selectivity-

${ }^{13}$ The article employs 6-point Gaussian and Laguerre quadrature techniques (Davis and Rabinowitz 1975).

${ }^{14}$ In practice, the estimation procedure did not exhibit these problems. Convergence was relatively rapid, and the final parameter estimates did not fall on any boundaries. 
corrected estimates of hourly wage rates to all mothers. Let wages be given by

$$
\ln W=\Lambda^{\prime} M+v
$$

where $M$ represents observed determinants and $v$ is a normally distributed error term. Equation (11) is estimated jointly with a labor force participation probit using maximum likelihood (Maddala 1983).

Estimating the determinants of paid care expenditures raises similar selectivity concerns. In the data, the care utilization decisions of nonworking women are not recorded. Expenditure amounts are also not observed for families who utilize unpaid care exclusively. In addition, expenditures over $\$ 100$ per week are censored. Let expenditures on child care be a general function of hours of work, other observed determinants, and unobserved determinants such that

$$
\ln P_{F}=g(H, D ; \Delta)+\zeta,
$$

where $D$ is a vector of observed variables, $\Delta$ is a vector of coefficients, and $\zeta$ is a normally distributed error term. Maximum likelihood is used to estimate the nonlinear expenditure specification (12) jointly with reducedform labor supply and care utilization equations. The econometric procedure accounts for the possible endogeneity of $H$, selectivity from $H$ and $F$, and censoring. A detailed description of the likelihood function appears in appendix B. ${ }^{15}$

To identify the wage and price parameters in the model, exclusion restrictions are imposed on the vectors $M$ and $D$ and on the exogenous determinants of $H$ and $F$. The model assumes that wages are a function of human capital, regional variation, and demand effects. Demand effects as measured by the local unemployment rate and average annual wage rate for private employers are assumed to have little direct effect on the decision variables and thus appear in the wage determinants only. The cost of market child care is assumed to be a function of quality, supply cost, and regional variation. From this list, supply cost, as measured by the local average salary for service workers, appears to be a reasonable candidate for identification.

\section{Data}

The primary empirical source for the analysis is the Survey of Income and Program Participation. The SIPP is a nationally representative longi-

${ }^{15}$ The article's imputation procedure for wages and care costs may be inappropriate because these variables enter the estimation function nonlinearly. 
tudinal sample that contains a wealth of demographic, income, and labor supply information. Observations are drawn from wave 5 of the 1984 panel which was fielded during the winter of 1984-85. Among the data collected in wave 5 were responses to a series of questions concerning child care.

In the SIPP, the available economic data include hours of work and earned and unearned income for everyone in the household 15 years of age and older. For this article, monthly totals for the economic variables are computed for the last full month prior to the interview date. The mother's monthly pretax unearned income is computed by aggregating the family's reported unearned income with the earned incomes of all other family members. Monthly hours of work and earned income are computed for "salaried" mothers (families with self-employed mothers are excluded from the extract).

The actual hourly wage rate for employed mothers is obtained by dividing monthly earned income by monthly hours. Parameter estimates from the selectivity-corrected log wage equation are used to predict pretax wages for each mother in the sample. Estimation results for the log wage equation appear in appendix C.

Applicable demographic variables drawn from the SIPP include the composition of the household, the ages and educational attainment of its members, the race of the household head, and the household location. The SIPP also contains information on the cost and utilization of child care arrangements. For employed mothers, child care data were recorded for the three youngest children under the age of 15 for 1 week in the month prior to the interview. Available information for each child includes the primary and secondary care mode choice. Data are also reported for families' total weekly child care expenditures. For families that utilize paid services, the article projects care expenditures to a monthly aggregate. Parameter estimates from selectivity- and endogeneity-corrected expenditure equations are used to predict pretax part-time and full-time care costs for each family. Estimation results are discussed in the next section.

The econometric analysis uses after-tax measures of monthly income with and without paid care expenditures at zero, part-time, and full-time hours. Monthly part-time hours are assumed to equal 86.6 (20 hours per week for 4.33 weeks), and full-time hours are assumed to equal 173.2 (40 hours per week for 4.33 weeks). ${ }^{16}$ For each of the five joint care and work categories, taxes are estimated by projecting the monthly pretax income to an annual total; allowing for the standard deduction, exemptions, and marriage penalty exclusion; computing the appropriate federal income tax amount (less the EITC and CDCTC, if applicable); computing the appli-

${ }^{16}$ These round figures are close to the conditional mean hours of work for partand full-time workers (21 and 41 hours, respectively) from the sample. 
cable social security taxes; and dividing by 12 . After-tax income then equals pretax income less estimated income and social security taxes.

The SIPP data include an important conditioning factor for the quality of care-the age of the child under care. Children of different ages require different types of care (Ruopp et al. 1979; Leibowitz et al. 1988). Younger children need to be monitored more intensively, in smaller groups than do older children. Educational requirements also vary by age. Differences in states' regulatory vigilance are used as additional indicators of quality (U.S. Department of Labor 1988). Variables include flags for states with relatively low mandated center child:staff ratios for 3-year-olds (ratios less than or equal to 10:1), states that check criminal and child abuse records of potential caregivers, and states that license and inspect family day care homes.

Two additional measures have been collected externally. The largest cost factor in paid care is wages paid to caregivers. Indeed, personnel expenses accounted for $69 \%$ of organized center costs in the 1976-77 National Day Care Survey (Ruopp et al. 1979). The article has obtained 1985 data on annual average salaries for service workers and all private employees in each state from the U.S. Department of Commerce Regional Economic Information System. Service worker wages are used to proxy differences in care provider wages between states. Total private earnings are taken to be a measure of local labor demand and cost of living conditions.

Means for the analysis variables are presented in table 1. Table 1 also lists means conditional on child care arrangement and mother's labor force participation. The analysis extract contains observations for 3,769 married families with at least one child under the age of 15 . Among these families, 1,983 had a mother who worked. Of the families with employed mothers, 649 reported using some form of paid care, and 1,334 reported using no paid care. Mothers who worked part-time were much less likely to utilize paid care than women who worked full-time (23\% vs. $40 \%) .{ }^{17}$

\section{Results}

\section{A. Child Care Expenditures}

Table 2 reports the results of three alternative specifications of the care expenditure equation (12). The three specifications are all restricted versions of the following model:

$$
\ln P_{F}=\Delta^{\prime} D+\Delta_{h 0} \ln \left(\Delta_{f 0}+H\right)+\zeta
$$

${ }^{17}$ A complete descriptive analysis of the data set appears in Ribar (1990). A general analysis of child care variables from the SIPP is given in U.S. Bureau of the Census (1987b). 
In the first specification in table $2, \Delta_{b 0}=1$ and $\Delta_{f 0}=0$; thus, similar to much of the existing literature, care costs are modeled as a flat hourly expense. Consistent with expectations, small children appear to have a strong positive effect on expenditures; older children have a weaker positive effect. Expenditures are higher for urban residents and residents of states with higher service worker wages. Expenditures are lower for residents of the South. One unexpected result is the significant negative coefficient on residence in a state with a low mandated child:staff ratio. The other two state-level quality variables are statistically insignificant.

The second specification in table 2 tests the linearity assumption from the previous model by relaxing the restriction on $\Delta_{b 0}$ and allowing expenditures to be a smooth nonlinear function in hours of work. The results strongly reject the assumption of linearity. In particular, the estimate on $\Delta_{h o}$ is significantly less than one, and the log likelihood increases substantially. The coefficient estimate indicates that child care expenditures increase with hours but at a decreasing rate. To provide a clearer picture of the implications of these results, table 3 reports the predicted expenditures under specifications 1 and 2 at alternative hours points using sample means for the independent variables. Although both specifications lead to similar predictions of full-time expenditures, the part-time costs generated by specification 2 are higher than those generated by specification 1 .

The third specification in table 2 presents an alternative test of the linearity assumption in which $\Delta_{b 0}$ is set at one but the restriction on $\Delta_{f o}$ is relaxed. This corresponds to an expenditure function with both fixed and linear marginal components. As in specification 2, the linearity assumption is strongly rejected. The estimates indicate that the average fixed costs of paid child care are $\$ 92$ per month ( $\$ 21$ per week) and that the marginal costs are $\$ 0.83$ per hour. In table 3 , the predicted full-time costs associated with specification 3 are again similar to those from the linear specification. The predicted costs at 86.6 hours are almost identical to the predictions from specification 2 .

Predicted expenditure/hours profiles from three other specifications are listed at the bottom of table 3. For brevity, individual coefficient estimates for these models are not listed. In specification 4, the log expenditure equation has been rewritten to include generally parameterized fixed and linear marginal components such that

$$
\ln P_{F}=\Delta^{\prime} D+\Delta_{b}^{\prime} D H+\zeta
$$

The predicted fixed costs are substantially higher and the implied marginal costs are much lower than in the previous specifications. Nevertheless, the predicted full-time expenditures from specification 4 are similar to those reported for the previous specifications. 


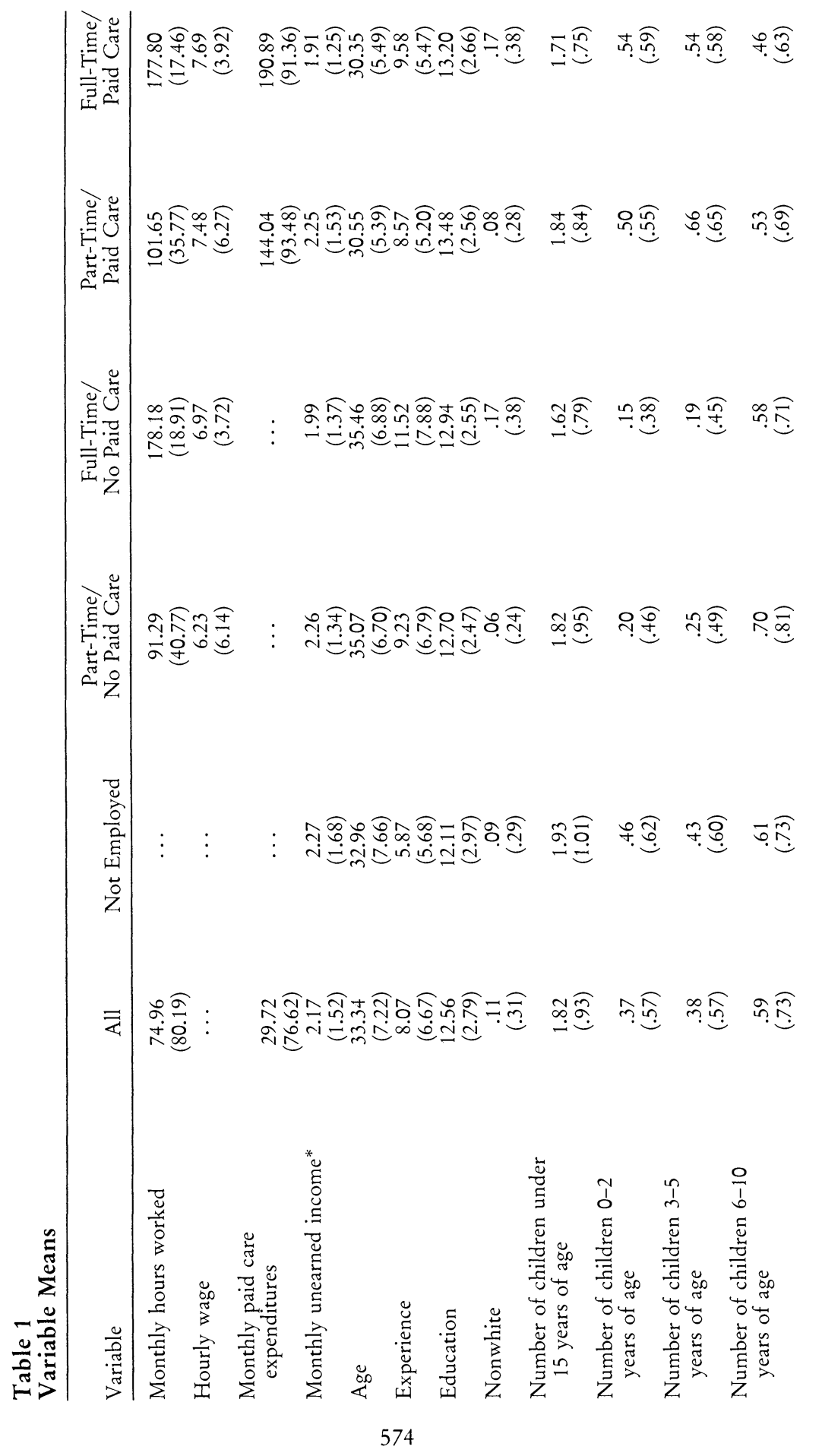




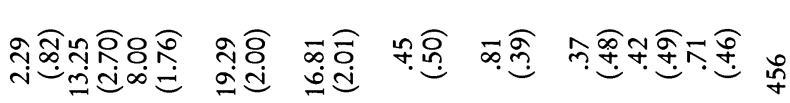

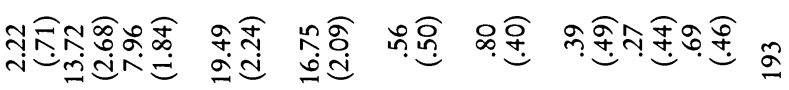

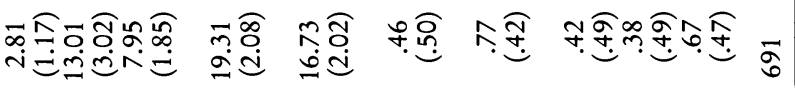

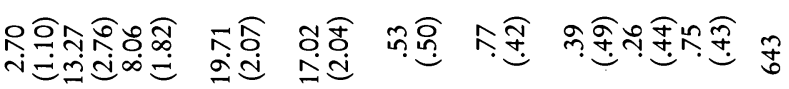

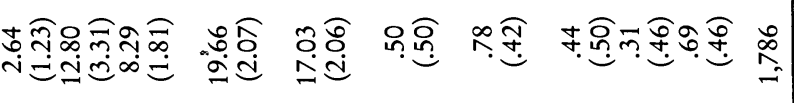

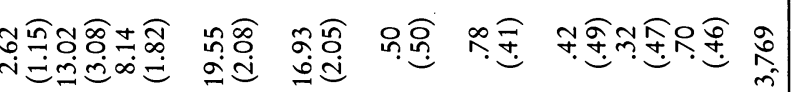

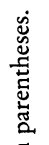

苛

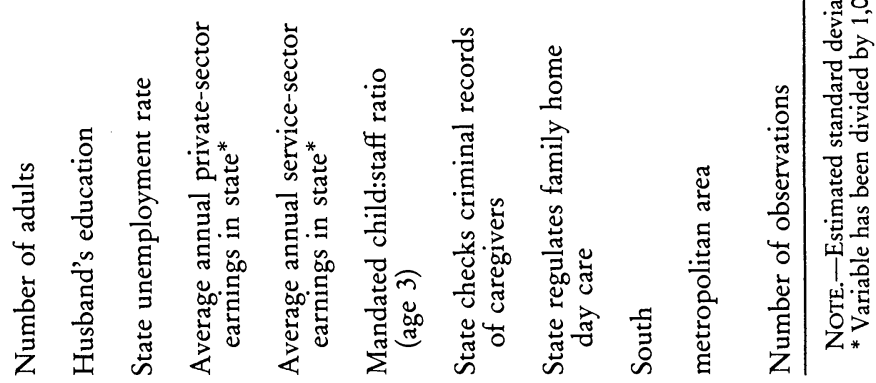


Table 2

\section{Child Care Expenditure Estimation Results}

\begin{tabular}{|c|c|c|c|}
\hline \multirow[b]{2}{*}{ Parameters } & \multicolumn{3}{|c|}{ Specifications } \\
\hline & (1) & (2) & (3) \\
\hline$\Delta_{1}=$ intercept & $\begin{array}{l}-.9096^{* * *} \\
(.2351)\end{array}$ & $\begin{array}{l}2.1339 * * * \\
(.4461)\end{array}$ & $\begin{array}{l}-1.0049^{* * *} \\
(.2160)\end{array}$ \\
\hline$\Delta_{2}=$ number of children 0-2 years of age & $\begin{array}{l}.4485^{* * *} \\
(.0569)\end{array}$ & $\begin{array}{l}.1804^{* * *} \\
(.0628)\end{array}$ & $\begin{array}{l}.1807^{* * *} \\
(.0631)\end{array}$ \\
\hline$\Delta_{3}=$ number of children $3-5$ years of age & $\begin{array}{l}.3891^{* * *} \\
(.0463)\end{array}$ & $\begin{array}{l}.0402^{* * *} \\
(.0485)\end{array}$ & $\begin{array}{l}.0027^{* * *} \\
(.0490)\end{array}$ \\
\hline$\Delta_{4}=$ number of children $6-10$ years of age & $\begin{array}{l}.0968^{* * *} \\
(.0362)\end{array}$ & $\begin{array}{l}.0671^{*} \\
(.0364)\end{array}$ & $\begin{array}{l}.0648^{*} \\
(.0358)\end{array}$ \\
\hline$\Delta_{5}=$ average annual service earnings in state ${ }^{\mathrm{a}}$ & $\begin{array}{l}.0467^{* * *} \\
(.0127)\end{array}$ & $\begin{array}{l}.0432^{* * *} \\
(.0127)\end{array}$ & $\begin{array}{l}.0414^{* * *} \\
(.0125)\end{array}$ \\
\hline$\Delta_{6}=$ mandated child:staff ratio & $\begin{array}{l}-.1169^{* *} \\
(.0529)\end{array}$ & $\begin{array}{l}-.1438^{* * *} \\
(.0544)\end{array}$ & $\begin{array}{l}-.1496^{* * *} \\
(.0547)\end{array}$ \\
\hline $\begin{aligned} \Delta_{7}= & \text { state checks criminal records of } \\
& \text { caregivers }\end{aligned}$ & $\begin{array}{l}-.0026 \\
(.0609)\end{array}$ & $\begin{array}{l}-.0037 \\
(.0625)\end{array}$ & $\begin{array}{r}-.0029 \\
(.0630)\end{array}$ \\
\hline$\Delta_{8}=$ state regulates family home day care & $\begin{aligned}-.0428 \\
(.0465)\end{aligned}$ & $\begin{array}{l}-.0645 \\
(.0486)\end{array}$ & $\begin{array}{l}-.0605 \\
(.0490)\end{array}$ \\
\hline$\Delta_{9}=$ South & $\begin{array}{l}-.1330^{* *} \\
(.0576)\end{array}$ & $\begin{array}{l}-.1399^{* *} \\
(.0594)\end{array}$ & $\begin{array}{l}-.1482^{* *} \\
(.0596)\end{array}$ \\
\hline$\Delta_{10}=$ metropolitan area & $\begin{array}{l}.0904^{*} \\
(.0541)\end{array}$ & $\begin{array}{l}.1090^{*} \\
(.0563)\end{array}$ & $\begin{array}{l}.1150^{* *} \\
(.0563)\end{array}$ \\
\hline$\Delta_{b 0}$ & 1.0000 & $\begin{array}{l}.4795^{* * *} \\
(.0648)\end{array}$ & 1.0000 \\
\hline$\Delta_{f 0}$ & $\cdots$ & $\ldots$ & $\begin{array}{l}110.9155^{* * *} \\
(31.4585)\end{array}$ \\
\hline$\sigma_{\zeta}$ & $\begin{array}{l}.5459^{* * *} \\
(.0249)\end{array}$ & $\begin{array}{l}.5969^{* * *} \\
(.0326)\end{array}$ & $\begin{array}{l}.6002^{* * *} \\
(.0337)\end{array}$ \\
\hline$\rho_{1}$ & $\begin{array}{l}-.3789^{* * *} \\
(.0653)\end{array}$ & $\begin{array}{l}.0020 \\
(.0903)\end{array}$ & $\begin{array}{l}-.0127 \\
(.0926)\end{array}$ \\
\hline$\rho_{2}$ & $\begin{array}{l}-.4072^{* * *} \\
(.1168)\end{array}$ & $\begin{array}{l}-.6392^{* * *} \\
(.0728)\end{array}$ & $\begin{array}{l}-.6447^{* * *} \\
(.0723)\end{array}$ \\
\hline $\begin{array}{l}\text { Log likelihood } \\
\text { Number of observations }\end{array}$ & $-14,760.59$ & $\begin{array}{c}-14,739.27 \\
3,750\end{array}$ & $-14,744.97$ \\
\hline
\end{tabular}

NOTE.-Standard errors appear in parentheses. The likelihood function appears in appendix B. Log expenditure equations are estimated jointly with an hours equation and a paid care utilization equation. The hours equation includes the variables listed above, plus age, age $^{2}$, experience, experience ${ }^{2}$, mother's and father's education, race, monthly unearned income, number of adults, state unemployment rate, and average annual private-sector earnings in state. The care utilization equation includes the same variables as does the hours equation with the exception of the state unemployment rate.

2 Variable has been divided by 1,000 .

* Significant at the .10 level.

** Significant at the .05 level.

*** Significant at the .01 level.

Specification 5 appends a quadratic term in hours to (14) so that $\log$ expenditures depend on a fixed component and a nonlinear variable component. The significant increase in the likelihood value indicates that specification 4 should be rejected in favor of specification 5 . The predicted fixed cost from specification 5 is similar to the fixed cost from specification 3. Predicted full-time expenditures are also close to previous estimates. 


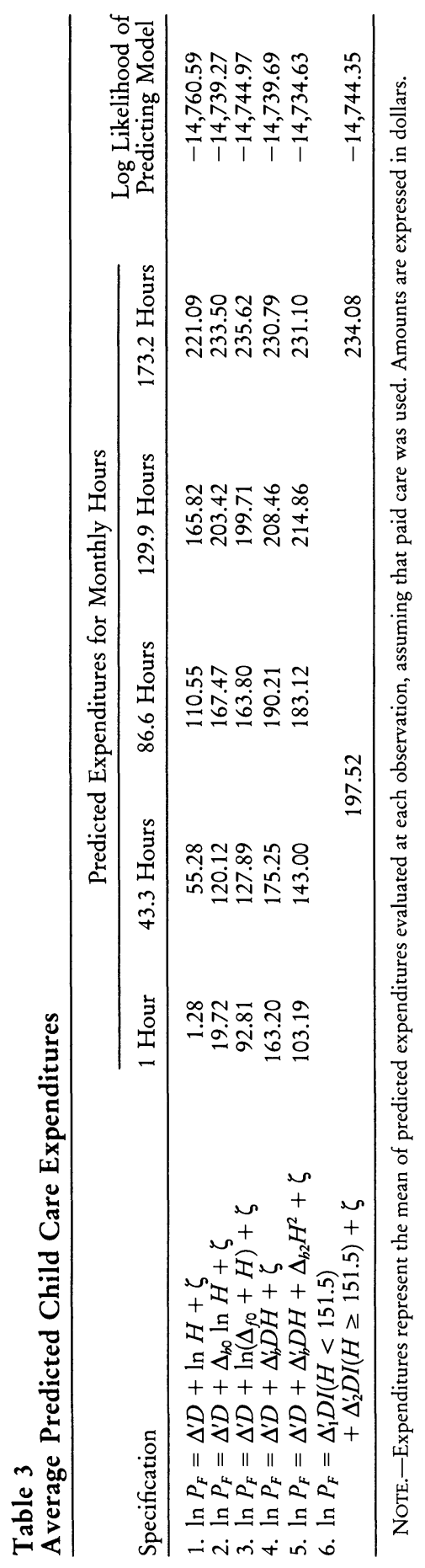


In the final specification, the observed determinants of expenditures are parameterized to have separate effects depending on whether the mother works full- or part-time. The cutoff between full- and part-time employment is defined as 151.5 hours per month ( 35 hours per week). Specification 6 yields predictions of full-time expenditures which are similar to the fulltime (173.2 hours) predictions from the previous models. Predicted parttime expenditures from specification 6 are higher than the previous predictions at 86.6 hours.

Choosing the best specification from the six listed in table 3 is problematic because not all of the models are nested. Clearly, specification 1 is rejected in favor of either specification 2 or 3 , and specification 4 is rejected in favor of specification 5. Beyond this point, however, nested comparisons are not possible. While predictions of full-time costs do not appear to be sensitive to the choice of model, there is considerable variation in the predicted part-time costs. In its imputations, the article uses specification 5 because it has the most general parameterization and yields a prediction for part-time expenditures which is in the middle of the range of estimates. ${ }^{18}$

\section{B. Structural Care Utilization and Labor Supply Results}

Table 4 reports results from four specifications of the structural econometric model. The first specification in table 4 is a restricted model in which the interaction terms $\gamma_{c b}$ and $\gamma_{c f}$ and the marginal parameter on paid care utilization, $\beta_{f}$, are set to zero. Thus, the family's objective function in specification 1 is a standard quadratic in income and hours of work with an interaction between hours of work and paid care utilization.

The first 10 coefficients $\left(\boldsymbol{\delta}_{1}-\boldsymbol{\delta}_{10}\right)$ in table 4 represent the effects of the listed variables on $\beta_{b}$, the marginal parameter on hours of work. A positive coefficient indicates that the variable has a positive effect on labor supply. For specification 1, standard results obtain. Labor supply decreases with the number of small children, the mother's age, and residence in a metropolitan area. Work experience, residence in the South, and being nonwhite are estimated to have positive effects on labor supply.

The next fourteen coefficients $\left(\psi_{1}-\psi_{14}\right)$ give the effects of the listed variables on the interaction between paid care utilization and hours of work. Positive coefficients are indicative of factors which make paid arrangements more attractive as labor supply increases. As expected, the number of small children, the mother's education, and residence in a metropolitan area increase the likelihood of paid care utilization. The mother's age and the number of adults in the household are estimated to have negative effects on paid care usage. As in the expenditure results, coefficients on the statelevel policy variables provide mixed support for hypotheses regarding care

${ }^{18}$ The estimates from the structural model are not sensitive to the choice of specifications $2,3,5$, or 6 . 
quality. While residence in a state that checks caregivers' criminal and child abuse backgrounds is associated with higher paid care utilization, residence in a state that regulates family home day care appears to decrease the attractiveness of paid care.

The next two parameters, $\theta_{c}$ and $\theta_{b}$, are the coefficients on the quadratic terms for income and hours of work. Both coefficients are positive and significant, indicating that the family's objective function is concave in income and labor supply. ${ }^{19}$ The final coefficients reported for specification 1 are the distributional parameters for $\varepsilon$ and $\eta$. Of note is the strong negative correlation between the unobserved determinants of labor supply and paid care interacted with labor supply.

The second specification in table 4 relaxes the restrictions on $\gamma_{c b}, \gamma_{c f}$, and $\beta_{f}$ and, thus, represents a fully parameterized version of the family's objective function. This specification allows for a richer set of cross-substitution effects than does the previous model. The added coefficients are individually and jointly significant. When the results are examined more closely, almost all of the coefficients and variance parameters increase in magnitude from specification 1 to specification 2. Although a few coefficients lose their significance, most of the substantive results from specification 1 are maintained. The changes in the coefficient estimates are likely the result of multicollinearity from the interaction terms.

In the third and fourth columns of table 4, specifications 1 and 2 are reestimated using a subsample of married women with at least one child under the age of 6 . Mothers of small children are examined because their care constraints are likely to be more pressing than the constraints for mothers of older children. The precise behavioral implications of these constraints, however, are unclear. On the one hand, the salience of the child care constraint might lead mothers of preschoolers to be more sensitive to changes in care costs. On the other hand, limited care options might decrease this group's observed sensitivity to changes in costs. The results from specifications 3 and 4 appear to be consistent with this second hypothesis.

Overall, the coefficient estimates from specification 3 are weaker than their counterparts from specification 1 . Among the labor supply parameters, the number of children from ages 6 to 10, residence in the South, and residence in an urban area lose their significance. The coefficients for the number of small children and the mother's age remain negative and significant; the coefficients on work experience and race remain positive and significant. When we turn to the paid care utilization parameters, the number of small children, the mother's age and education, residence in an

${ }^{19}$ The size of $\theta_{c}$ further implies that utility increases up to annual incomes of about $\$ 222,000$ and, thus, increases across the range of net incomes recorded and projected in the sample. 


\begin{tabular}{|c|c|c|c|c|}
\hline \multirow[b]{2}{*}{ Parameter } & \multicolumn{2}{|c|}{$\begin{array}{l}\text { Women with Children } \\
\text { under } 15 \text { Years of Age }\end{array}$} & \multicolumn{2}{|c|}{$\begin{array}{l}\text { Women with Children } \\
\text { under } 6 \text { Years of Age }\end{array}$} \\
\hline & (1) & $(2)$ & (3) & (4) \\
\hline$\delta_{1}=$ constant & $\begin{array}{l}2.174^{* * *} \\
(.757)\end{array}$ & $\begin{array}{l}8.677^{* *} \\
(3.697)\end{array}$ & $\begin{array}{c}2.018 \\
(1.389)\end{array}$ & $\begin{array}{c}12.224 \\
(10.389)\end{array}$ \\
\hline 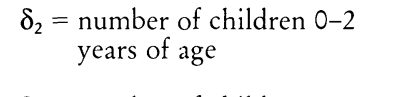 & $\begin{array}{l}-2.773^{* * *} \\
(.250)\end{array}$ & $\begin{array}{l}-7.592^{* * *} \\
(2.311)\end{array}$ & $\begin{array}{l}-2.211^{* * *} \\
(.439)\end{array}$ & $\begin{array}{l}-8.408 \\
(5.695)\end{array}$ \\
\hline $\begin{array}{c}\delta_{3}=\text { number of children } 3-5 \\
\text { years of age }\end{array}$ & $\begin{array}{l}-1.658^{* * *} \\
(.207)\end{array}$ & $\begin{array}{l}-4.645^{* * *} \\
(1.504)\end{array}$ & $\begin{array}{l}-.851^{* *} \\
(.337)\end{array}$ & $\begin{array}{r}-3.303 \\
(2.503)\end{array}$ \\
\hline $\begin{array}{c}\delta_{4}=\text { number of children } 6-10 \\
\text { years of age }\end{array}$ & $\begin{array}{l}-.428^{* * *} \\
(.121)\end{array}$ & $\begin{array}{c}-1.094^{* *} \\
(.440)\end{array}$ & $\begin{array}{l}.141 \\
(.262)\end{array}$ & $\begin{array}{l}-.571 \\
(1.019)\end{array}$ \\
\hline$\delta_{5}=$ mother's age & $\begin{array}{l}-.151^{* * *} \\
(.020)\end{array}$ & $\begin{array}{l}-.376^{* * * *} \\
(.114)\end{array}$ & $\begin{array}{l}-.250^{* * *} \\
(.054)\end{array}$ & $\begin{aligned}-.936 \\
(.676)\end{aligned}$ \\
\hline$\delta_{6}=$ mother's education & $\begin{array}{l}.049 \\
(.044)\end{array}$ & $\begin{array}{l}.346^{* * *} \\
(.171)\end{array}$ & $\begin{array}{l}.131 \\
(.093)\end{array}$ & $\begin{array}{l}1.238 \\
(.999)\end{array}$ \\
\hline$\delta_{7}=$ nonwhite & $\begin{array}{l}1.369^{* * *} \\
(.292)\end{array}$ & $\begin{array}{l}3.809^{* * *} \\
(1.347)\end{array}$ & $\begin{array}{l}1.998^{* * *} \\
(.580)\end{array}$ & $\begin{array}{c}9.181 \\
(6.817)\end{array}$ \\
\hline$\delta_{8}=$ South & $\begin{array}{l}.633^{* * *} \\
(.193)\end{array}$ & $\begin{array}{l}1.595^{* *} \\
(.677)\end{array}$ & $\begin{array}{l}.586 \\
(.414)\end{array}$ & $\begin{array}{l}3.835 \\
(3.296)\end{array}$ \\
\hline$\delta_{9}=$ metropolitan area & $\begin{aligned}-.350^{*} \\
(.195)\end{aligned}$ & $\begin{array}{c}-.564 \\
(.536)\end{array}$ & $\begin{array}{c}-.229 \\
(.358)\end{array}$ & $\begin{array}{l}-.510 \\
(1.326)\end{array}$ \\
\hline$\delta_{10}=$ experience & $\begin{array}{l}.213^{* * *} \\
(.022)\end{array}$ & $\begin{array}{l}.611^{* * * *} \\
(.183)\end{array}$ & $\begin{array}{l}.360^{* * *} \\
(.078)\end{array}$ & $\begin{array}{l}1.673 \\
(1.251)\end{array}$ \\
\hline$\psi_{1}=$ constant & $\begin{array}{l}1.776^{* * * *} \\
(.555)\end{array}$ & $\begin{array}{l}6.884^{* * *} \\
(2.570)\end{array}$ & $\begin{array}{c}1.523 \\
(1.080)\end{array}$ & $\begin{array}{r}3.720^{*} \\
(2.251)\end{array}$ \\
\hline $\begin{aligned} \psi_{2}= & \text { number of children } 0-2 \\
& \text { years of age }\end{aligned}$ & $\begin{array}{l}1.489^{* * * *} \\
(.309)\end{array}$ & $\begin{array}{l}4.443^{* * *} \\
(1.711)\end{array}$ & $\begin{array}{l}.160 \\
(.275)\end{array}$ & $\begin{array}{l}.468 \\
(.312)\end{array}$ \\
\hline $\begin{aligned} \psi_{3}= & \text { number of children } 3-5 \\
& \text { years of age }\end{aligned}$ & $\begin{array}{l}1.440 * * * \\
(.304)\end{array}$ & $\begin{array}{l}4.002^{* *} \\
(1.555)\end{array}$ & $\begin{array}{l}-.0005 \\
(.261)\end{array}$ & $\begin{array}{l}.208 \\
(.210)\end{array}$ \\
\hline $\begin{aligned} \psi_{4}= & \text { number of children } 6-10 \\
& \text { years of age }\end{aligned}$ & $\begin{array}{l}.012 \\
(.093)\end{array}$ & $\begin{array}{l}.195 \\
(.241)\end{array}$ & $\begin{array}{l}-.683^{* *} \\
(.338)\end{array}$ & $\begin{array}{r}-.326 \\
(.219)\end{array}$ \\
\hline$\psi_{5}=$ mother's age & $\begin{array}{l}-.068^{* * *} \\
(.019)\end{array}$ & $\begin{array}{l}-.173^{* *} \\
(.071)\end{array}$ & $\begin{array}{l}.009 \\
(.025)\end{array}$ & $\begin{aligned}-.002 \\
(.017)\end{aligned}$ \\
\hline$\psi_{6}=$ mother's education & $\begin{array}{l}.058^{*} \\
(.034)\end{array}$ & $\begin{array}{l}.059 \\
(.082)\end{array}$ & $\begin{array}{l}.111 \\
(.084)\end{array}$ & $\begin{array}{r}-.015 \\
(.048)\end{array}$ \\
\hline$\psi_{7}=$ nonwhite & $\begin{array}{l}.150 \\
(.196)\end{array}$ & $\begin{array}{c}-.053 \\
(.517)\end{array}$ & $\begin{array}{l}.454 \\
(.403)\end{array}$ & $\begin{array}{r}-.012 \\
(.251)\end{array}$ \\
\hline$\psi_{8}=$ South & $\begin{array}{l}-.055 \\
(.162)\end{array}$ & $\begin{array}{l}-.121 \\
(.417)\end{array}$ & $\begin{array}{l}.688 \\
(.471)\end{array}$ & $\begin{array}{l}.354 \\
(.322)\end{array}$ \\
\hline$\psi_{9}=$ metropolitan area & $\begin{array}{l}.238^{*} \\
(.142)\end{array}$ & $\begin{array}{l}.303 \\
(.379)\end{array}$ & $\begin{aligned}-.150 \\
(.295)\end{aligned}$ & $\begin{aligned}-.126 \\
(.232)\end{aligned}$ \\
\hline$\psi_{10}=$ number of adults & $\begin{array}{l}-.281^{* * *} \\
(.090)\end{array}$ & $\begin{array}{l}-.623^{* *} \\
(.282)\end{array}$ & $\begin{aligned}-.276^{*} \\
(.158)\end{aligned}$ & $\begin{aligned}-.206 \\
(.139)\end{aligned}$ \\
\hline$\psi_{11}=$ husband's education & $\begin{aligned}-.019 \\
(.025)\end{aligned}$ & $\begin{array}{l}-.046 \\
(.063)\end{array}$ & $\begin{array}{r}-.079 \\
(.057)\end{array}$ & $\begin{aligned}-.028 \\
(.040)\end{aligned}$ \\
\hline$\psi_{12}=$ mandated child:staff ratio & $\begin{array}{l}-.223 \\
(.136)\end{array}$ & $\begin{array}{l}-.434 \\
(.344)\end{array}$ & $\begin{array}{l}-.050 \\
(.265)\end{array}$ & $\begin{array}{l}.061 \\
(.221)\end{array}$ \\
\hline $\begin{aligned} \psi_{13}= & \text { state checks criminal } \\
& \text { records of caregivers }\end{aligned}$ & $\begin{array}{l}.264^{*} \\
(.154)\end{array}$ & $\begin{array}{l}.559 \\
(.407)\end{array}$ & $\begin{array}{l}.146 \\
(.295)\end{array}$ & $\begin{array}{l}-.032 \\
(.230)\end{array}$ \\
\hline
\end{tabular}


Table 4 (Continued)

\begin{tabular}{|c|c|c|c|c|}
\hline \multirow[b]{2}{*}{ Parameter } & \multicolumn{2}{|c|}{$\begin{array}{l}\text { Women with Children } \\
\text { under } 15 \text { Years of Age }\end{array}$} & \multicolumn{2}{|c|}{$\begin{array}{l}\text { Women with Children } \\
\text { under } 6 \text { Years of Age }\end{array}$} \\
\hline & (1) & $(2)$ & (3) & $(4)$ \\
\hline $\begin{array}{c}\psi_{14}=\text { state regulates family } \\
\text { home day care }\end{array}$ & $\begin{array}{c}-.239^{*} \\
(.130)\end{array}$ & $\begin{array}{c}-.481 \\
(.336)\end{array}$ & $\begin{array}{c}-.350 \\
(.250)\end{array}$ & $\begin{array}{c}-.135 \\
.175)\end{array}$ \\
\hline$\theta_{c}(\times 1,000)$ & $.027^{* *}$ & -.160 & $.082^{* * *}$ & .042 \\
\hline$\theta_{b}$ & $\begin{array}{l}(.012) \\
.015^{* * *} \\
(.001)\end{array}$ & $\begin{array}{l}(.111) \\
.041^{* * *} \\
(.011)\end{array}$ & $\begin{array}{l}(.023) \\
.016^{* * *} \\
(.002)\end{array}$ & $\begin{array}{l}(.097) \\
.056^{*} \\
(.033)\end{array}$ \\
\hline$\gamma_{c b}$ & $\ldots$ & $\begin{array}{r}-.002^{*} \\
(.001)\end{array}$ & $\ldots$ & $\begin{array}{c}-.003 \\
(.003)\end{array}$ \\
\hline$\gamma_{c f}$ & $\cdots$ & $\begin{array}{l}.090^{* *} \\
(.046)\end{array}$ & $\cdots$ & $\begin{array}{c}.028 \\
(.045)\end{array}$ \\
\hline$\beta_{f}$ & $\cdots$ & $\begin{array}{c}-397.849^{* *} \\
(164.712)\end{array}$ & $\cdots$ & $\begin{array}{c}-189.686 \\
(168.029)\end{array}$ \\
\hline$\sigma_{\eta}$ & $\begin{array}{l}4.266^{* * *} \\
(.271)\end{array}$ & $\begin{array}{l}11.455^{* * *} \\
(3.314)\end{array}$ & $\begin{array}{l}5.227^{* * *} \\
(.684)\end{array}$ & $\begin{array}{c}20.486 \\
(13.774)\end{array}$ \\
\hline$\sigma_{\mathrm{B}}$ & $\begin{array}{l}2.074^{* * *} \\
(.508)\end{array}$ & $\begin{array}{l}5.862^{* *} \\
(2.395)\end{array}$ & $\begin{array}{l}3.013^{* *} \\
(1.286)\end{array}$ & $\begin{array}{c}2.069^{*} \\
(1.124)\end{array}$ \\
\hline$\rho_{\eta \mathrm{B}}$ & $\begin{array}{l}-.411^{* * *} \\
(.068)\end{array}$ & $\begin{array}{l}-.647^{* * *} \\
(.062)\end{array}$ & $\begin{array}{l}-.278^{* *} \\
(.137)\end{array}$ & $\begin{array}{l}-.509^{* * *} \\
(.120)\end{array}$ \\
\hline Log likelihood & $-4,458.64$ & $-4,441.26$ & $-2,466.65$ & $-2,431.11$ \\
\hline Number of observations & & 769 & & 060 \\
\hline
\end{tabular}

NOTE.-Standard errors appear in parenthes̀es.

* Significant at the .10 level.

** Significant at the .05 level.

*** Significant at the .01 level.

urban area, and the state quality variables lose their significance. The number of children from ages 6 to 10 and the number of adults in the household are each estimated to have significant negative effects on paid care utilization. As in specification 1, the family's objective function appears to be concave in income and hours of work. There also still appears to be a significant negative correlation between $\varepsilon$ and $\eta$.

When the interaction terms are added in specification 4, the log likelihood increases dramatically. However, virtually all of the estimated coefficients lose their individual significance. As in specification 2, the contradictory results suggest that the addition of interactions leads to multicollinearity.

The economic implications of the results from the four structural specifications are summarized in table 5. For each specification, table 5 reports elasticities of the labor force participation and care utilization decisions with respect to changes in after-tax wages, care costs, and unearned incomes. The estimates in table 5 have been obtained by taking means of the relevant elasticities calculated for each individual in the sample.

The results from specifications 1 and 2 indicate that married women's employment has a small negative income elasticity and that paid care utilization among working women has a small positive income elasticity. 
Table 5

Estimated Elasticities

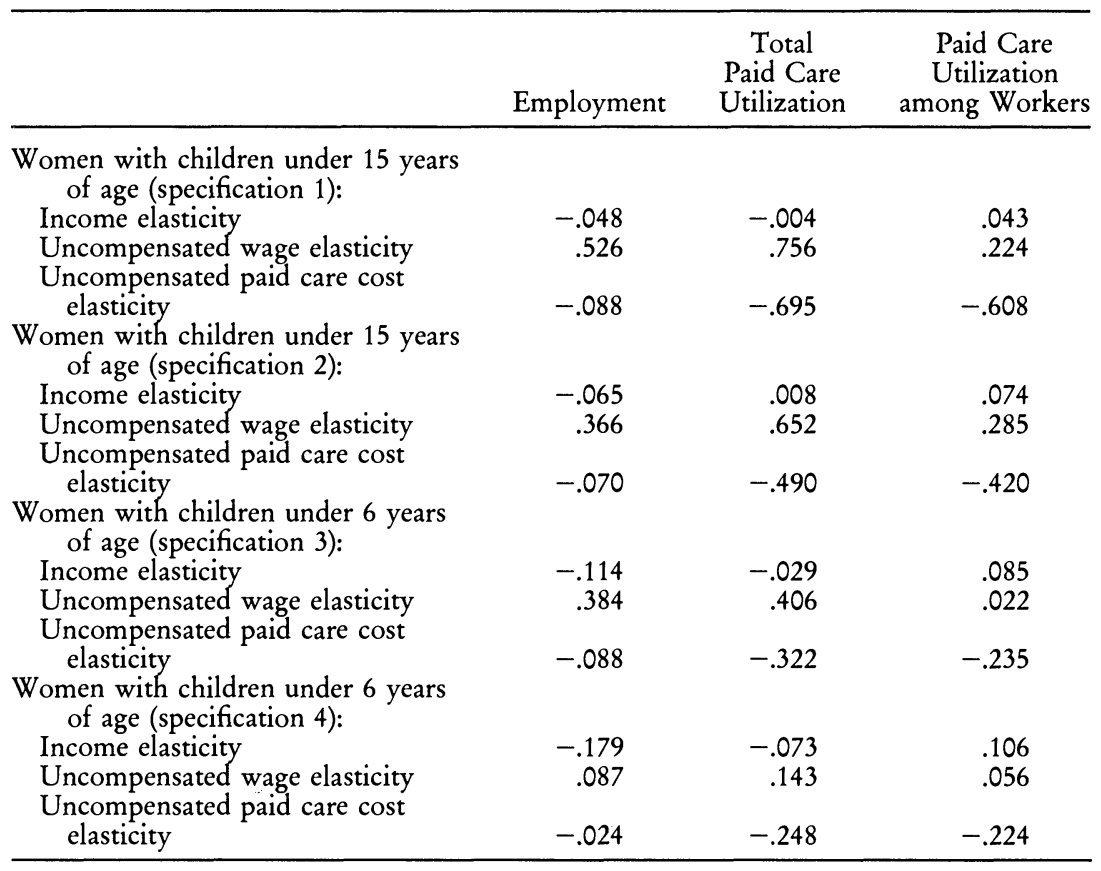

NOTE.-Reported elasticities represent mean of effects evaluated at each observation.

Assuming that nonworking women use no paid care, the combination of these effects implies that overall utilization is almost perfectly income inelastic. From specifications 3 and 4, mothers of preschoolers appear to be more sensitive to changes in unearned income than are mothers generally.

Employment and paid care utilization for married women with children under 15 are estimated to be relatively sensitive to wage changes. The uncompensated wage elasticities for employment and paid care utilization conditional on employment range from .366 to .526 and .224 to .285 , respectively. The wage elasticities with respect to employment are close to the estimates reported by Kimmel (1993) but higher than those reported by Michalopoulos et al. (1992). The wage elasticities for paid care are similar to Michalopoulos et al.'s estimate of .17. Table 5 indicates that mothers of preschoolers are less sensitive to wage changes with employment and conditional paid care elasticities of .087-.384 and .022-.056.

The results from all four specifications indicate that changes in care costs have very little effect on married mothers' employment. The elasticities from table 5 are similar to estimates reported by Michalopoulos et al. and lower than the estimates reported by Blau and Robins (1988), Connelly (1992), Ribar (1992), and Kimmel (1993). Care costs appear 
to have strong negative effects on paid care utilization. As with the wage results, the effects are larger for mothers generally than for mothers of preschoolers. Overall, the results suggest that increases in care costs cause mothers to switch care arrangements but not to leave the labor force.

\section{Policy Implications}

As a final exercise, the article reports the results of several policy simulations in tables 6 and 7. Table 6 lists the predicted total, part-time, and full-time employment levels associated with different policies as well as predicted levels of paid care utilization conditional on employment status. Descriptions of the effects of the policy changes on the CDCTC appear in table 7 . In particular, table 7 lists changes in the potential annual subsidies for part- and full-time workers, the average annual subsidies received by all families, and the average annual subsidies received by families who claim the CDCTC. As in the previous table, the predicted outcomes in tables 6 and 7 represent means of expected values evaluated at each observation in the data set. Because of the range of model estimates, predictions based on all four specifications are reported.

The first row in table 6 lists the actual employment and care utilization rates from the sample. Baseline simulations from specifications 1 and 2 come very close to replicating the actual results for all women. Both specifications slightly underpredict part-time employment and overpredict fulltime employment. Specification 1 also appears to overpredict paid care utilization for part-timers and underpredict utilization for full-timers. Specifications 3 and 4 generate reasonable predictions of the employment and care utilization rates for women with preschool children, though the predictions are a little less accurate than those for the full sample. Of the two specifications, 3 appears to be slightly more accurate in the baseline than 4.

The predicted baseline subsidy amounts for each specification are reported in table 7. Internal Revenue Service data indicate that the average subsidy in 1985 for married families who filed jointly and claimed the CDCTC was $\$ 340$ (U.S. Department of the Treasury 1988). Though these data are only roughly comparable, they suggest that subsidies may be overpredicted in table 7.

The first policy change that the article considers is the elimination of the CDCTC. Clearly, eliminating the CDCTC is neither a serious nor likely policy option. However, the simulation is useful in illustrating the sensitivity of employment and care utilization to tax policy in 1985. Estimates reveal that the CDCTC had a strong positive effect on paid care utilization, especially paid care utilization among women who worked part-time. The CDCTC appears to have had only a modest effect on labor 


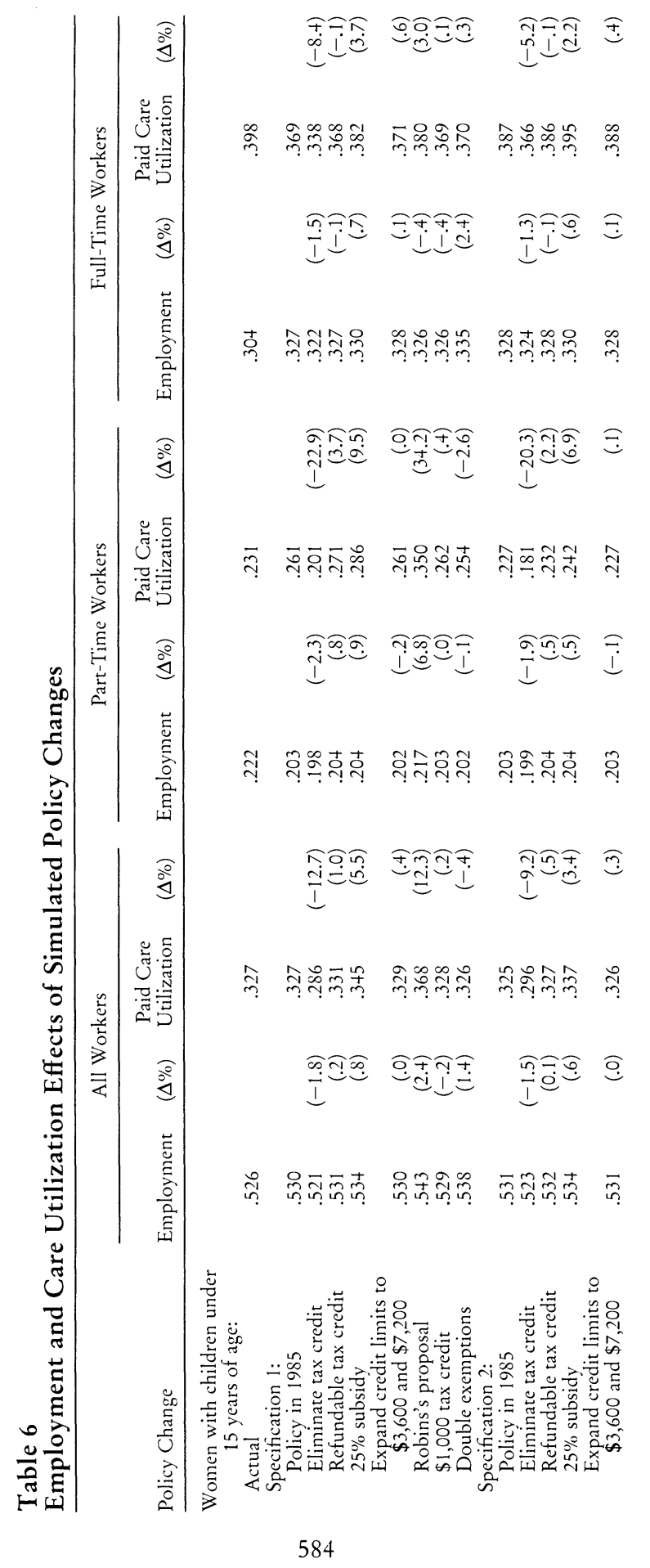


ลูํำ

$$
\text { } \text { iิ }
$$

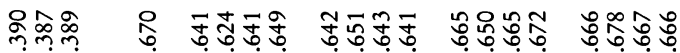

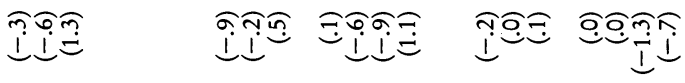

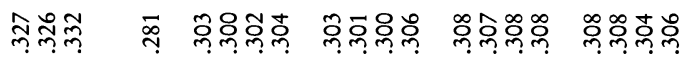

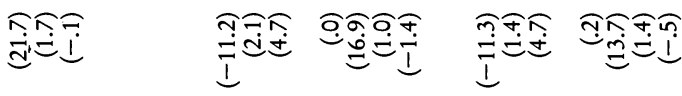

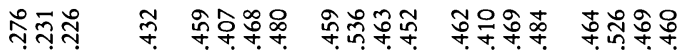

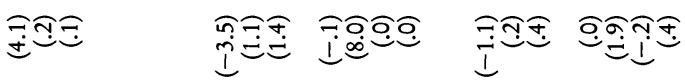

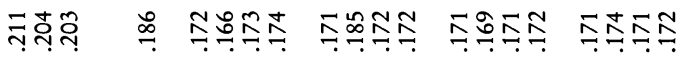

ํำ

过

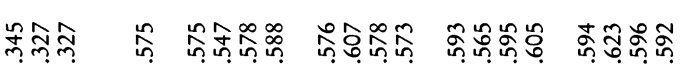

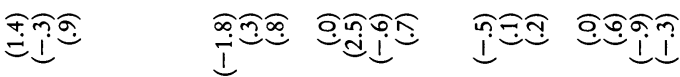

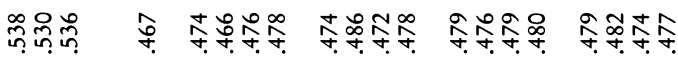

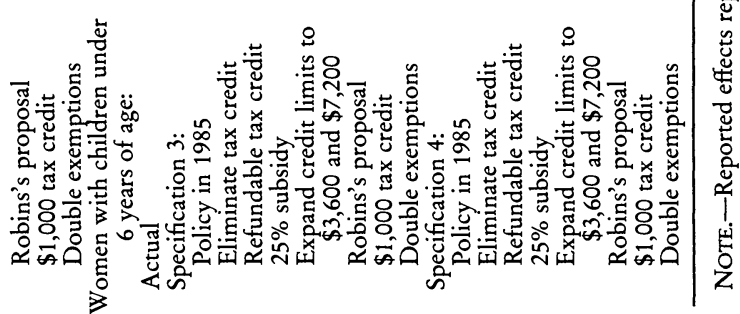




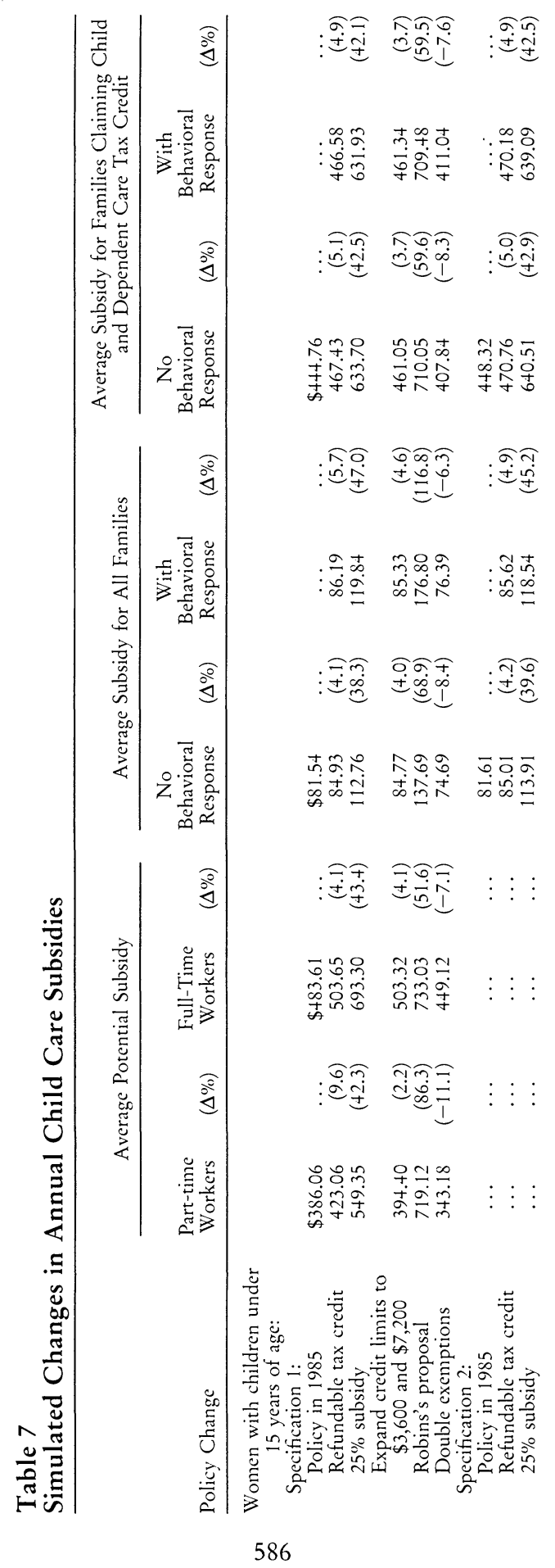




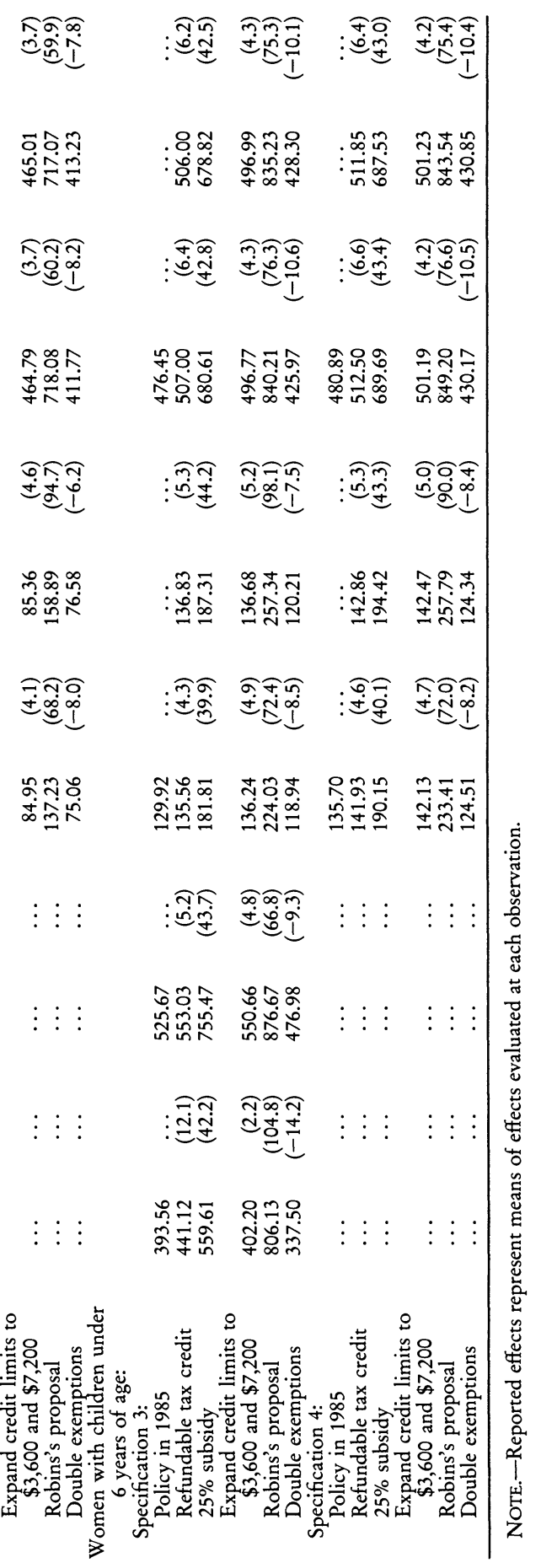


force participation. Eliminating the tax credit would have reduced married women's employment by no more than 1 percentage point.

The second policy change examined in tables 6 and 7 is a proposal to make the CDCTC fully refundable. A refundable CDCTC would benefit low-income families with little or no tax liability. From table 7, the average potential annual subsidies to part- and full-time workers increase by $\$ 37$ and $\$ 20$, respectively. The corresponding increases for mothers of preschool-age children are $\$ 48$ and $\$ 27$. These changes have virtually no effect on employment or paid care utilization. Indeed, the only discernible effect from making the CDCTC refundable is a small increase in paid care utilization among part-time workers. While refundability has little effect on behavior, the policy does have other distributional implications (for discussions of this issue, see Barnes 1988 and Robins 1988b).

The article next considers the effects of replacing the CDCTC with a flat $25 \%$ subsidy on child care expenditures. Unlike the tax credit, the subsidy is fully refundable, is not adjusted for income, and has no upper limit. Under this scheme, the potential subsidies for part- and full-time workers would increase by roughly $40 \%$. Despite its large cost, the flat subsidy would have almost no effect on married women's labor force participation and only a small effect on paid care utilization. As in the two previous simulations, most of the increase in paid care use would come from women working part-time.

Another proposal is to increase the eligible expenses under the CDCTC to $\$ 3,600$ for one child and $\$ 7,200$ for two or more children. In principle, this proposal would help middle- and upper-income families whose potential benefits under the CDCTC have been eroded by inflation. ${ }^{20} \mathrm{How}^{-}$ ever, the policy change has little practical effect on average benefits in table 7 because few families in the sample incurred expenses in excess of the existing CDCTC maximums. Not surprisingly, the behavioral effect of increasing eligible expenditures is negligible.

The article next considers a comprehensive proposal which has been put forward by Robins (1988b). He recommended making three modifications to the current tax credit: (1) make the tax credit refundable, (2) increase the eligible expenses to $\$ 3,600$ and $\$ 7,200$, and (3) establish a sliding scale for expenses starting at $80 \%$ for families earning less than $\$ 10,000$. Robins's proposal is very generous-the potential benefits for part- and full-time workers increase by $86.3 \%$ and $51.6 \%$, respectively.

${ }^{20}$ When it was introduced in 1976 , the CDCTC covered $20 \%$ of the first $\$ 2,000$ in care expenses for one child and the first $\$ 4,000$ in expenses for two or more children. When the CDCTC was changed from a flat percentage to a sliding (30\%$20 \%$ ) scale in 1982, the eligible expenses were reset to $\$ 2,400$ for one child and $\$ 4,800$ for two or more children. These nominal limits have not been subsequently adjusted. Thus, the real value of the CDCTC has declined for upper-income families since 1976 and for all families since 1982. 
The results from table 6 indicate his plan leads to a moderate increase in part-time employment, a small increase in full-time paid arrangements, and a larger increase in part-time paid arrangements. These behavioral effects, especially the expansion of paid care use, would increase the realized cost of Robins's plan substantially.

Finally, the article examines two proposals which have been periodically discussed by politicians. The first of these is a plan, which was offered by President Bush during the 1988 campaign, to extend a large refundable tax credit to all families with children. The tax credit would not have been conditioned on parents' employment and, thus, would have acted as an income subsidy. Table 6 considers the effects of a $\$ 1,000$ annual subsidy. The simulation results indicate that a $\$ 1,000$ credit would not affect parttime employment but would increase paid care utilization among parttimers. Full-time employment would decrease slightly, though paid care usage among full-timers would not change.

A second proposal which has been discussed by Senator Daniel Moynihan (e.g., Moynihan 1987) is to expand the size of exemptions under the federal income tax code. Tables 6 and 7 simulate the effects of doubling the exemptions for each family member in 1985 from $\$ 1,040$ to $\$ 2,080$. While the proposal is operationally straightforward, it affects families' employment and child care incentives in a complicated way. Increasing the size of exemptions reduces the average family's tax liability by sheltering a larger portion of income from taxation and lowering the marginal rate on the last dollar earned. At the same time, effective subsidies for paid care decrease because of the nonrefundability of the CDCTC. This is illustrated in table 7 where the potential subsidies for part- and full-time workers diminish by $\$ 43$ and $\$ 34$, respectively. Though there is a range of estimates, the simulations in table 6 generally predict that doubling the exemptions would increase full-time employment and decrease paid care utilization among part-time workers.

\section{Conclusion}

This article uses 1984-85 data from the SIPP to examine the structure of child care costs and the effects of care costs on married women's employment and care utilization decisions. The article finds that child care expenditures are a nonlinear function of hours of work. In particular, expenditures appear to entail a substantial fixed component as well as a nonlinear marginal component. A structural discrete-choice labor supply and care utilization model is estimated. The econometric methodology allows women's work and child care decisions to be endogenous determinants of one another and accounts for nonlinearities in families' budget constraints which arise from the care expenditure function and the U.S. tax system. Estimates based on this model indicate that married women's labor supply is relatively insensitive to changes in care costs. Child care 
subsidy programs such as the CDCTC appear to influence women's care decisions but have little effect on their employment.

While the article provides interesting and important results, several avenues remain open for future research. A serious limitation in the present analysis is the broad definition of care modes. Grouping all purchased care into one category simplifies estimation but may mask differences in costs, quality, and preferences. More complicated structural econometric techniques (e.g., the Simulated Method of Moments estimator for nonlinear budget sets recently developed by Keane and Moffitt [1991]) which allow for expanded choice sets should be considered. Another constraint on the analysis is the lack of direct information on the quality attributes of care. State-level data are used; however, community- and center-specific information would be more appropriate. Data on quality "outcomes" such as developmental effects would also be helpful. Future work should also consider other family decisions such as husband's labor supply and parents' fertility. Both decisions increase the dimensionality of the problem. A model of joint family labor supply would be useful in examining the determinants of shift work; a model of fertility would be useful in examining quality and quantity trade-offs. A final avenue would be to extend the analysis to single-parent families. Here program participation decisions complicate the budget constraint and increase the dimensionality of the problem. Nevertheless, such an analysis would help to inform the debate on the relationship between child care and economic self-sufficiency.

\section{Appendix A}

\section{Derivation of Structural Labor Supply and Care Utilization Likelihood Function}

Denote the maternal labor supply choices as $H_{0}, H_{1}$, and $H_{2}$. Let

$$
\begin{aligned}
D(H, F)= & Y(H, F)-\theta_{c} Y(H, F)^{2}-\theta_{b} H^{2} \\
& +\beta_{f} F+\gamma_{c b} Y(H, F) H+\gamma_{c f} Y(H, F) F,
\end{aligned}
$$

and let

$$
\begin{aligned}
Q_{1} & =\frac{D\left(H_{0}, 0\right)-D\left(H_{2}, 0\right)}{H_{2}}-\delta^{\prime} Z, \\
Q_{2} & =\frac{D\left(H_{1}, 0\right)-D\left(H_{2}, 0\right)}{H_{2}-H_{1}}-\delta^{\prime} Z, \\
Q_{3} & =\frac{D\left(H_{2}, 0\right)-D\left(H_{2}, 1\right)}{H_{2}}-\psi^{\prime} X, \\
Q_{4} & =\frac{D\left(H_{1}, 1\right)-D\left(H_{2}, 0\right)+H_{1} \psi^{\prime} X}{H_{2}-H_{1}}-\delta^{\prime} Z, \\
Q_{5} & =\frac{D\left(H_{0}, 0\right)-D\left(H_{2}, 1\right)}{H_{2}}-\delta^{\prime} Z-\psi^{\prime} X,
\end{aligned}
$$




$$
\begin{aligned}
& Q_{6}=\frac{D\left(H_{1}, 0\right)-D\left(H_{2}, 1\right)-H_{2} \psi^{\prime} X}{H_{2}-H_{1}}-\delta^{\prime} Z, \\
& Q_{7}=\frac{D\left(H_{1}, 1\right)-D\left(H_{2}, 1\right)}{H_{2}-H_{1}}-\delta^{\prime} Z-\psi^{\prime} X, \\
& Q_{8}=\frac{D\left(H_{0}, 0\right)-D\left(H_{1}, 0\right)}{H_{1}}-\delta^{\prime} Z, \\
& Q_{9}=\frac{D\left(H_{1}, 0\right)-D\left(H_{1}, 1\right)}{H_{1}}-\psi^{\prime} X, \\
& Q_{10}=\frac{D\left(H_{0}, 0\right)-D\left(H_{1}, 1\right)}{H_{1}}-\delta^{\prime} Z-\psi^{\prime} X .
\end{aligned}
$$

State 1: if $H=H_{0}$ and $F=0$,

$\tilde{U}\left(Y\left(H_{0}, 0\right), H_{0}, 0\right)>\tilde{U}\left(Y\left(H_{1}, 0\right), H_{1}, 0\right)$ implies $\eta<Q_{8}$, $\tilde{U}\left(Y\left(H_{0}, 0\right), H_{0}, 0\right)>\tilde{U}\left(Y\left(H_{2}, 0\right), H_{2}, 0\right)$ implies $\eta<Q_{1}$, $\tilde{U}\left(Y\left(H_{0}, 0\right), H_{0}, 0\right)>\tilde{U}\left(Y\left(H_{1}, 1\right), H_{1}, 1\right)$ implies $\eta+\varepsilon<Q_{10}$, $\tilde{U}\left(Y\left(H_{0}, 0\right), H_{0}, 0\right)>\tilde{U}\left(Y\left(H_{2}, 1\right), H_{2}, 1\right)$ implies $\eta+\varepsilon<Q_{5}$,

$$
\begin{gathered}
W_{1}=\min \left(Q_{1}, Q_{8}\right), \quad W_{2}=\min \left(Q_{5}, Q_{10}\right), \\
\operatorname{prob}\left(H=H_{0}, F=0\right)=\int_{-\infty}^{W_{1}} \int_{-\infty}^{W_{2}-\eta} f(\varepsilon, \eta) d \varepsilon d \eta .
\end{gathered}
$$

State 2: if $H=H_{1}$ and $F=0$,

$\tilde{U}\left(Y\left(H_{1}, 0\right), H_{1}, 0\right)>\tilde{U}\left(Y\left(H_{0}, 0\right), H_{0}, 0\right)$ implies $\eta>Q_{8}$, $\tilde{U}\left(Y\left(H_{1}, 0\right), H_{1}, 0\right)>\tilde{U}\left(Y\left(H_{2}, 0\right), H_{2}, 0\right)$ implies $\eta<Q_{2}$, $\tilde{U}\left(Y\left(H_{1}, 0\right), H_{1}, 0\right)>\tilde{U}\left(Y\left(H_{1}, 1\right), H_{1}, 1\right)$ implies $\varepsilon<Q_{9}$, $\tilde{U}\left(Y\left(H_{1}, 0\right), H_{1}, 0\right)>\tilde{U}\left(Y\left(H_{2}, 1\right), H_{2}, 1\right)$ implies $\eta+\varepsilon \frac{H_{2}}{H_{2}-H_{1}}<Q_{6}$, $T_{2}=\left(Q_{6}-Q_{8}\right) \frac{H_{2}-H_{1}}{H_{2}}, \quad T_{3}=\min \left(Q_{3}, Q_{9}\right), \quad T_{4}=\min \left(T_{2}, Q_{9}\right)$, $\operatorname{prob}\left(H=H_{1}, F=0\right)=\int_{-\infty}^{T_{3}} \int_{Q_{8}}^{Q_{2}} f(\varepsilon, \eta) d \eta d \varepsilon$

$$
+I\left(Q_{3}<Q_{9}\right) \int_{Q_{3}}^{T_{4}} \int_{Q_{8}}^{Q_{6}-\varepsilon\left[H_{2} /\left(H_{2}-H_{1}\right)\right]} f(\varepsilon, \eta) d \eta d \varepsilon
$$


State 3: if $H=H_{2}$ and $F=0$,

$\tilde{U}\left(Y\left(H_{2}, 0\right), H_{2}, 0\right)>\tilde{U}\left(Y\left(H_{0}, 0\right), H_{0}, 0\right)$ implies $\eta>Q_{1}$,

$\tilde{U}\left(Y\left(H_{2}, 0\right), H_{2}, 0\right)>\tilde{U}\left(Y\left(H_{1}, 0\right), H_{1}, 0\right)$ implies $\eta>Q_{2}$,

$\tilde{U}\left(Y\left(H_{2}, 0\right), H_{2}, 0\right)>\tilde{U}\left(Y\left(H_{2}, 1\right), H_{2}, 1\right)$ implies $\varepsilon<Q_{3}$,

$\tilde{U}\left(Y\left(H_{2}, 0\right), H_{2}, 0\right)>\tilde{U}\left(Y\left(H_{1}, 1\right), H_{1}, 1\right)$ implies $\eta-\varepsilon \frac{H_{1}}{H_{2}-H_{1}}>Q_{4}$,

$R_{1}=\max \left(Q_{1}, Q_{2}\right), \quad R_{2}=\left(R_{1}-Q_{4}\right) \frac{H_{2}-H_{1}}{H_{1}}, \quad R_{3}=\min \left(Q_{3}, R_{2}\right)$,

$\operatorname{prob}\left(H=H_{2}, F=0\right)=\int_{-\infty}^{R_{3}} \int_{R_{1}}^{\infty} f(\varepsilon, \eta) d \eta d \varepsilon$

$+I\left(R_{2}<Q_{3}\right) \int_{R_{2}}^{Q_{3}} \int_{Q_{4}+\varepsilon\left[H_{1} /\left(H_{2}-H_{1}\right)\right]}^{\infty} f(\varepsilon, \eta) d \eta d \varepsilon$.

State 4: if $H=H_{1}$ and $F=1$,

$\tilde{U}\left(Y\left(H_{1}, 1\right), H_{1}, 1\right)>\tilde{U}\left(Y\left(H_{0}, 0\right), H_{0}, 0\right)$ implies $\eta+\varepsilon>Q_{10}$,

$\tilde{U}\left(Y\left(H_{1}, 1\right), H_{1}, 1\right)>\tilde{U}\left(Y\left(H_{1}, 0\right), H_{1}, 0\right) \quad$ implies $\varepsilon>Q_{9}$,

$\tilde{U}\left(Y\left(H_{1}, 1\right), H_{1}, 1\right)>\tilde{U}\left(Y\left(H_{2}, 0\right), H_{2}, 0\right)$ implies $\eta-\varepsilon \frac{H_{1}}{H_{2}-H_{1}}<Q_{4}$,

$\tilde{U}\left(Y\left(H_{1}, 1\right), H_{1}, 1\right)>\tilde{U}\left(Y\left(H_{2}, 1\right), H_{2}, 1\right) \quad$ implies $\eta+\varepsilon<Q_{7}$,

$V_{1}=\left(Q_{10}-Q_{4}\right) \frac{H_{2}-H_{1}}{H_{2}}, \quad V_{3}=\max \left(V_{1}, Q_{9}\right), \quad V_{4}=\max \left(Q_{3}, Q_{9}\right)$,

$\operatorname{prob}\left(H=H_{1}, F=1\right)=\int_{V_{4}}^{\infty} \int_{\mathrm{Q}_{10}-\varepsilon}^{\mathrm{Q}_{7}-\varepsilon} f(\varepsilon, \eta) d \eta d \varepsilon$

$+I\left(Q_{3}>Q_{9}\right) \int_{V_{3}}^{Q_{3}} \int_{Q_{10}-\varepsilon}^{Q_{4}+\varepsilon\left[H_{1} /\left(H_{2}-H_{1}\right)\right]} f(\varepsilon, \eta) d \eta d \varepsilon$

State 5: if $H=H_{2}$ and $F=1$,

$\tilde{U}\left(Y\left(H_{2}, 1\right), H_{2}, 1\right)>\tilde{U}\left(Y\left(H_{0}, 0\right), H_{0}, 0\right)$ implies $\eta+\varepsilon>Q_{5}$, $\tilde{U}\left(Y\left(H_{2}, 1\right), H_{2}, 1\right)>\tilde{U}\left(Y\left(H_{1}, 0\right), H_{1}, 0\right)$ implies $\eta+\varepsilon \frac{H_{2}}{H_{2}-H_{1}}>Q_{6}$, 


$$
\begin{aligned}
& \tilde{U}\left(Y\left(H_{2}, 1\right), H_{2}, 1\right)> \tilde{U}\left(Y\left(H_{2}, 0\right), H_{2}, 0\right) \text { implies } \varepsilon>Q_{3}, \\
& \tilde{U}\left(Y\left(H_{2}, 1\right), H_{2}, 1\right)>\tilde{U}\left(Y\left(H_{1}, 1\right), H_{1}, 1\right) \text { implies } \eta+\varepsilon>Q_{7}, \\
& S_{1}=\max \left(Q_{5}, Q_{7}\right), \quad S_{2}=\left(Q_{6}-S_{1}\right) \frac{H_{2}-H_{1}}{H_{1}}, \quad S_{3}=\max \left(Q_{3}, S_{2}\right), \\
& \operatorname{prob}\left(H=H_{2}, F=1\right)= \\
& \quad \int_{S_{3}}^{\infty} \int_{S_{1}-\varepsilon}^{\infty} f(\varepsilon, \eta) d \eta d \varepsilon \\
&+I\left(Q_{3}<S_{2}\right) \int_{Q_{3}}^{S_{2}} \int_{Q_{6}-\varepsilon\left[H_{2} /\left(H_{2}-H_{1}\right)\right]}^{\infty} f(\varepsilon, \eta) d \eta d \varepsilon
\end{aligned}
$$

\section{Appendix B}

\section{Derivation of the Child Care Expenditure Likelihood Functions}

Consider a reduced-form Tobit specification for monthly hours of work:

$$
\begin{gathered}
H^{*}=\Gamma_{b}^{\prime} X_{b}+\varepsilon_{b}, \\
H= \begin{cases}0 & \text { if } H^{*} \leq 0, \\
H^{*} & \text { if } H^{*}>0 .\end{cases}
\end{gathered}
$$

Conditional on hours being positive, the family's care utilization decision is observed. A reduced-form description of the decision to pay for care, $F$, can be written

$$
\begin{gathered}
F^{*}=\Gamma_{f}^{\prime} X_{f}+\varepsilon_{f}, \\
F= \begin{cases}0 \text { (do not pay for care) } & \text { if } F^{*} \leq 0, \\
1 \text { (pay for care) } & \text { if } F^{*}>0 .\end{cases}
\end{gathered}
$$

Expenditures are observed conditional on hours and the decision to pay for care being positive. Expenditures above $P_{m}(\$ 100$ per week and $\$ 433$ per month) are censored at $P_{m}$. Finally, let the error terms $\varepsilon_{b}$, $\varepsilon_{f}$, and $\zeta$ be distributed as

$$
\left[\begin{array}{c}
\varepsilon_{h} \\
\varepsilon_{f} \\
\zeta
\end{array}\right] \sim N\left(\left[\begin{array}{l}
0 \\
0 \\
0
\end{array}\right],\left[\begin{array}{ccc}
\sigma_{b}^{2} & \rho_{h f} \sigma_{b} & \rho_{1} \sigma_{b} \sigma_{\zeta} \\
& 1 & \rho_{2} \sigma_{\zeta} \\
& & \sigma_{\zeta}^{2}
\end{array}\right]\right)
$$


Let

$$
\begin{gathered}
z_{b}=\frac{H-\Gamma_{b}^{\prime} X_{b}}{\sigma_{b}}, \quad z_{f}=-\Gamma_{f}^{\prime} X_{f}, \\
z_{p}=\frac{\ln P_{F}-g(H, D ; \Delta)}{\sigma_{\zeta}}, \quad z_{m}=\frac{\ln P_{m}-g(H, D ; \Delta)}{\sigma_{\zeta}} .
\end{gathered}
$$

Then

$$
\begin{gathered}
\operatorname{prob}(H=0)=\Phi\left(z_{h}\right) \\
\operatorname{prob}(H>0, F=0)=\sigma_{b}^{-1} \int_{-\infty}^{z_{f}} \phi_{2}\left(z_{b}, \varepsilon_{f}^{*} ; \rho_{h f}\right) d \varepsilon_{f}^{*}, \\
\operatorname{prob}\left(H>0, F=1, P_{F}<P_{m}\right) \\
=\left(\sigma_{b} \sigma_{\zeta}\right)^{-1} \int_{z_{f}}^{\infty} \phi_{3}\left(z_{h}, \varepsilon_{f}^{*}, z_{p} ; \rho_{h f}, \rho_{1}, \rho_{2}\right) d \varepsilon_{f}^{*} \\
\operatorname{prob}\left(H>0, F=1, P_{F}=P_{m}\right) \\
=\sigma_{b}^{-1} \int_{z_{f}}^{\infty} \int_{z_{m}}^{\infty} \phi_{3}\left(z_{b}, \varepsilon_{f}^{*}, \zeta^{*} ; \rho_{h f}, \rho_{1}, \rho_{2}\right) d \zeta^{*} d \varepsilon_{f}^{*} .
\end{gathered}
$$

\begin{tabular}{|c|c|c|c|c|}
\hline \multirow[b]{3}{*}{ Variable } & \multicolumn{4}{|c|}{ Dependent Variables } \\
\hline & \multicolumn{2}{|c|}{ Log Wage } & \multicolumn{2}{|c|}{$\begin{array}{l}\text { Labor Force } \\
\text { Participation }\end{array}$} \\
\hline & Result & $\mathrm{SE}$ & Result & SE \\
\hline Intercept & -.1435 & .2963 & -.0817 & .5050 \\
\hline Age & .0159 & .0149 & .0205 & .0250 \\
\hline $\operatorname{Age}^{2 a}$ & -.0333 & .0217 & $-.0955^{* * *}$ & .0354 \\
\hline Experience & $.0437^{* * *}$ & .0054 & $.1133^{* * *}$ & .0064 \\
\hline Experience $^{2 a}$ & $-.0508 * * *$ & .0141 & $-.1333 * * *$ & .0167 \\
\hline Education & $.0738^{* * *}$ & .0043 & $.0750^{* * *}$ & .0110 \\
\hline State unemployment & $-.0157^{* *}$ & .0066 & $-.0461^{* * *}$ & .0144 \\
\hline \multicolumn{5}{|l|}{ Average annual private-sector earnings } \\
\hline in state ${ }^{b}$ & $.0205^{* * *}$ & .0069 & .0386 & .0247 \\
\hline South & .0380 & .0281 & .0860 & .0612 \\
\hline Metropolitan area & $.0940 * * *$ & .0287 & $.0969^{*}$ & .0542 \\
\hline Nonwhite & .0586 & .0358 & $.2542 * * *$ & .0739 \\
\hline Unearned income $e^{b}$ &... & $\ldots$ & $-.1146^{* * *}$ & .0162 \\
\hline Number of children $0-2$ years of age & $\ldots$ & $\ldots$ & $-.5268^{* * *}$ & .0464 \\
\hline Number of children $3-5$ years of age & $\ldots$ & $\ldots$ & $-.2416^{* * *}$ & .0409 \\
\hline Number of children $6-10$ years of age & $\ldots$ & $\ldots$ & -.0489 & .0305 \\
\hline Number of adults & $\ldots$ & $\ldots$ & $.0474^{* *}$ & .0212 \\
\hline Husband's education & $\ldots$ & $\ldots$ & -.0075 & .0098 \\
\hline
\end{tabular}

\section{Appendix C}

Table C1

Joint Log Wage, Labor Force Participation Results 
Table C1 (Continued)

\begin{tabular}{|c|c|c|c|c|}
\hline \multirow[b]{3}{*}{ Variable } & \multicolumn{4}{|c|}{ Dependent Variables } \\
\hline & \multicolumn{2}{|c|}{ Log Wage } & \multicolumn{2}{|c|}{$\begin{array}{l}\text { Labor Force } \\
\text { Participation }\end{array}$} \\
\hline & Result & $\mathrm{SE}$ & Result & $\mathrm{SE}$ \\
\hline \multicolumn{5}{|l|}{$\begin{array}{l}\text { Average annual service-sector earnings } \\
\text { in state }\end{array}$} \\
\hline State child:staff ratio & $\cdots$ & $\cdots$ & -.0646 & .0519 \\
\hline State checks criminal records & $\ldots$ & $\ldots$ & .0757 & .0599 \\
\hline State regulates family home day care & ... & .. & $-.0925^{*}$ & .0486 \\
\hline$\sigma$ & $.5139^{* * *}$ & .0102 & $\ldots$ & $\ldots$ \\
\hline$\rho$ & $.3002^{* * *}$ & .0969 & $\ldots$ & $\ldots$ \\
\hline Log likelihood & \multicolumn{4}{|c|}{$-3,646.34$} \\
\hline Number of observations & 3 & & & \\
\hline
\end{tabular}

2 Variable has been divided by 100 .

b Variable has been divided by 1,000 .

* Significant at the .10 level.

** Significant at the .05 level.

*** Significant at the .01 level.

\section{References}

Averett, Susan; Peters, H. Elizabeth; and Waldman, Donald. "Tax Credits, Labor Supply, and Child Care." Unpublished manuscript. Easton, PA: Lafayette College, November 1992.

Barnes, Roberta. "The Distributional Effects of Alternative Child Care Proposals." Paper presented at the meetings of the Association for Public Policy Analysis and Management, Seattle, WA, October 1988.

$\rightarrow$ Berger, Mark, and Black, Dan. "Child Care Subsidies, Quality of Care, and the Labor Supply of Low-Income, Single Mothers." Review of Economics and Statistics 74 (November 1992): 635-42.

Berndt, E.; Hall, B.; Hall, R.; and Hausman, J. "Estimation and Inference in Nonlinear Structural Models." Annals of Econometric and Social Measurement 3 (1974): 653-66.

Blau, David. "The Labor Market Effects of Child Care Subsidies." Unpublished manuscript. Chapel Hill: University of North Carolina, April 1989.

$\rightarrow-$ " "The Child Care Labor Market." Journal of Human Resources 27 (Winter 1992): 9-39.

$\rightarrow$ Blau, David, and Robins, Philip. "Child-Care Costs and Family Labor Supply." Review of Economics and Statistics 70 (August 1988): 374-81.

- "Fertility, Employment, and Child Care Costs." Demography 26 (May 1992): 287-99.

Cogan, John. "Labor Supply with Costs of Labor Market Entry." In Female Labor Supply: Theory and Estimation, edited by James Smith, pp. 32764. Princeton, NJ: Princeton University Press, 1980.

Connelly, Rachel. "The Cost of Child Care and Single Mothers: Its Effect on Labor Force Participation and AFDC Recipiency." Unpublished manuscript. Brunswick, ME: Bowdoin College, March 1990. 
. "The Effect of Child Care Costs on Married Women's Labor Force Participation." Review of Economics and Statistics 74 (February 1992): 83-90.

Davis, Philip J., and Rabinowitz, Philip. Methods of Numerical Integration. New York: Academic Press, 1975.

Folk, Karen Fox, and Beller, Andrea. "Joint Choice of Child Care and Labor Supply by Mothers of Preschool Children." Unpublished manuscript. Urbana: University of Illinois, November 1991.

Fraker, Thomas, and Moffitt, Robert. "The Effect of Food Stamps on Labor Supply: A Bivariate Selection Model." Journal of Public Economics 35 (February 1988): 1-24.

Hausman, Jerry. "Labor Supply." In How Taxes Affect Economic Behavior, edited by H. Aaron and J. Pechman. Washington, DC: Brookings Institute, 1981.

- "The Econometrics of Nonlinear Budget Sets." Econometrica 53 (November 1985): 1255-82.

Heckman, James. "Effects of Child-Care Programs on Women's Work Effort." Journal of Political Economy 82, suppl. (March-April 1974): 13663.

$\rightarrow$ Hofferth, Sandra, and Wissoker, Douglas. "Price, Quality, and Income in Child Care Choice." Journal of Human Resources 27 (Winter 1992): 70111.

Hotz, V. Joseph, and Kilburn, M. Rebecca. "The Demand for Child Care and Child Care Costs: Should We Ignore Families with Non-working Mothers?" Unpublished manuscript. Chicago: University of Chicago, December 1991.

Keane, Michael, and Moffitt, Robert. "A Structural Model of Multiple Welfare Program Participation and Labor Supply." Unpublished manuscript. Providence, RI: Brown University, October 1991.

Kimmel, Jean. "Child Care Costs as a Barrier to Employment for Single and Married Mothers." Unpublished manuscript. Kalamazoo, MI: W. E. Upjohn Institute for Employment Research, September 1993.

Kisker, Ellen; Maynard, Rebecca; Gordon, Anne; and Strain, Margaret. "The Child Care Challenge: What Parents Need and What Is Available in Three Metropolitan Areas." Unpublished manuscript. Princeton, NJ: Mathematica Policy Research, February 1989.

Lehrer, Evelyn. "Preschoolers with Working Mothers: An Analysis of the Determinants of Child Care Arrangements." Journal of Population Economics 1 (March 1989): 251-68.

Lehrer, Evelyn, and Kawasaki, Seiichi. "Child Care Arrangements and Fertility: An Analysis of Two-Earner Households." Demography 22 (November 1985): 499-513.

Leibowitz, Arleen; Klerman, Jacob; and Waite, Linda. "Employment of New Mothers and Child Care Choice." Journal of Human Resources 27 (Winter 1992): 112-34.

Leibowitz, Arleen; Waite, Linda; and Witsberger, Christina. "Child Care for Preschoolers: Differences by Child's Age.” Demography 25 (May 1988): 205-20. 
Maddala, G. S. Limited-Dependent and Qualitative Variables in Econometrics. Cambridge: Cambridge University Press, 1983.

$\rightarrow$ Michalopoulos, Charles; Robins, Philip; and Garfinkel, Irwin. "A Structural Model of Labor Supply and Child Care Demand." Journal of Human Resources 27 (Winter 1992): 166-203.

$\rightarrow$ Moffitt, Robert. "The Econometrics of Kinked Budget Constraints." Journal of Economic Perspectives 4 (February 1990): 119-39.

$\rightarrow$ Moffitt, Robert, and Wolfe, Barbara. "The Effect of the Medicaid Program on Welfare Participation and Labor Supply." Review of Economics and Statistics 74 (November 1992): 615-26.

Moynihan, Daniel. Family and Nation. New York: Harcourt Brace Jovanovich, 1987.

Ribar, David. "Child Care and the Labor Supply of Married Women." Ph.D. dissertation. Providence, RI: Brown University, July 1990.

"Child Care and the Labor Supply of Married Women: Reduced Form Evidence." Journal of Human Resources 27 (Winter 1992): 134-65.

Robins, Philip. "Child-Care and Convenience: The Effects of Labor Market Entry Costs on Economic Self-Sufficiency among Public Housing Residents." Social Science Quarterly 69 (March 1988): 122-36. (a)

"Federal Support for Child Care: Current Policies and a Proposed

New System." Focus 11 (Summer 1988): 1-9. (b)

Robins, Philip, and Spiegelman, Robert. "An Econometric Model of the Demand for Child Care." Economic Inquiry 16 (January 1978): 83-94.

Ruopp, Richard; Travers, Jeffrey; Glantz, Frederic; and Coelen Craig. The National Day Care Study, vol. 1. Cambridge, MA: Abt Books, 1979.

U.S. Bureau of the Census. Survey of Income and Program Participation Users' Guide. Washington, DC: U.S. Government Printing Office, 1987. (a)

"Who's Minding the Kids? Child Care Arrangements: Winter 198485." Current Population Reports, Series P-70:9. Washington, DC: U.S. Government Printing Office, 1987. (b)

-. "Who's Minding the Kids? Child Care Arrangements: Fall 1988." Current Population Reports, Series P-70:30. Washington, DC: U.S. Government Printing Office, 1992.

U.S. Department of Labor. Child Care: A Workforce Issue. Washington, DC: U.S. Government Printing Office, 1988.

U.S. Department of the Treasury. Statistics of Income-1985: Individual Income Tax Returns. Washington, DC: U.S. Government Printing Office, 1988.

Walker, James. "New Evidence on the Supply of Child Care." Journal of Human Resources 27 (Winter 1992): 40-69. 